\title{
Selection of parameters in nanosecond pulsed wave laser micro-welding
}

\author{
Julio Coroado $^{1} \cdot$ Supriyo Ganguly ${ }^{1} \cdot$ Wojciech Suder $^{1} \cdot$ Stewart Williams $^{1} \cdot$ Sonia Meco ${ }^{1} \cdot$ Goncalo Pardal $^{1}$
}

Received: 29 November 2020 / Accepted: 6 May 2021 / Published online: 31 May 2021

(C) The Author(s) 2021

\begin{abstract}
The digital control of the latest nanosecond pulsed wave (PW) fibre lasers allows very high flexibility in controlling the application of the total energy to a workpiece, which brings several advantages to the joining process. By choosing different pulse shapes in different spatial profiles, it is possible to apply low energy per pulse with high precision and accuracy resulting in lower heat input. Since the energy of each pulse is insufficient to generate melting, these lasers operate at very high pulse repetition frequencies near continuous wave $(\mathrm{CW})$ regime. Nevertheless, the peak powers of $\mathrm{PW}$ lasers are much higher than $\mathrm{CW}$. In this research, the effect of peak power, pulse energy, pulse width, pulse repetition frequency and duty cycle has been studied. The experimental work was conducted in bead on plate of austenitic stainless steel to investigate the effect of laser on the weld geometry, i.e. depth of penetration and width. An empirical model, previously established for $\mathrm{CW}$ mode, which enables the achievement of a particular penetration depth independent of the beam diameter, was redesigned and tested for PW mode. The "pulse power factor model" allows the laser user to select a weld profile that meets certain quality and productivity requirements independent of the laser system. It was shown that identical depth of penetration but different weld metal profile can be obtained for a specific beam diameter for a range of different system parameters by keeping a constant trade-off between pulse power factor and interaction time.
\end{abstract}

Keywords Micro-welding $\cdot$ Pulse power factor model $\cdot$ Interaction time $\cdot$ Depth of penetration $\cdot$ Weld shape

\section{Introduction}

Laser welding is a non-contact process for joining both similar and dissimilar materials. This technique introduces the innovation needed to substitute the traditional tool wearing contact methods, such as mechanical clinching or friction stir welding, improving productivity using ultra-fast scanning devices. It has a good potential in micro-joining due to the high energy density, resulting in a very precise heat input control and high penetration/width ratio when compared to other fusion welding processes $[1,2]$. Its versatility in the manufacturing of precision components ensures the required quality standards for electrical and mechanical connections without a filling material. Nevertheless, it is necessary to have a very accurate positioning $[3,4]$. For a butt-joint configuration, for instance, the presence of a gap between the base materials is

Julio Coroado

julio.coroado@gmail.com

1 Welding Engineering and Laser Processing Centre, Cranfield University, Cranfield MK43 0AL, UK critical, being important to avoid that the beam passes through without interacting with the joining partners [5]. Therefore, a robust experimental setup is necessary to ensure repetitive and reliable results [6].

$\mathrm{CW}$ lasers can be applied in a wider range of material thicknesses due to their higher average power in comparison to PW lasers, which allows better productivity through faster processing speeds to minimise the heat input [7]. The deep penetration and good weld quality of $\mathrm{CW}$ mode are attributed to the stable heat conduction mechanism to the metal, since the peak power is always constant during the irradiation time, which does not happen in PW mode [8]. The most recent generation of PW fibre lasers have low operating and maintenance costs and the laser beam can be easily delivered to the workpiece due to its high optical quality $\left(\mathrm{M}^{2}<1.6\right)$. These lasers provide a cost-effective solution, being integrated into different industrial applications given the variety of temporal pulse shapes, also known as waveforms [9, 10]. Normally nanosecond lasers are used for material removal processes such as cutting [11], drilling [12], engraving and machining $[13,14]$ due to short pulse duration and high peak powers, but when operated at a high repetition rate, they can be used for 
precision welding [15], being able to minimise thermal damages, welding distortion and porosity formation [16]. However, in some applications, where higher fit-up tolerance and penetration depth are required, the $\mathrm{CW}$ lasers are often the best choice [17, 18].

The selection of different parameters in laser welding is complex as there are many variables to control for specific applications such as power, welding speed or beam diameter which affect the weld profile differently. Moreover, the material type and its application also affect the response to the laser energy. Laser welding of austenitic stainless steel is normally applied in nuclear structural fabrication, valve bodies and vessel internals because of the excellent mechanical properties achieved [19]. It is also used to precisely join small cylindrical cells and large cells with geometrical large interconnectors in automotive battery packs [20]. Kuryntsev et al. observed the benefits of tuning the beam diameter according to the laser application [21]. Using defocused beams, they increased the volume of the weld pool of stainless steel, reducing the requirement for preparation of edge and gap between workpieces [21]. In a different study, the volume of the weld pool was controlled by controlling the pulse shape [22]. Kumar et al. found that the fusion zone area and the penetration depth of stainless-steel welds decreased when the pulse width was increased beyond $5 \mathrm{~ms}$. Nonetheless, the ultimate tensile strength of all the welded joints at different pulse widths was similar [22]. Modelling approaches have also been carried out to predict the required time for reaching melting temperature in each laser pulse [23], and the optimal process parameters for producing the expected welding bead profile [24].

In summary, PW lasers enable finer control of material interaction because the same pulse energy can be applied with different combinations of pulse width, peak power and pulse energy. For nanosecond PW lasers, these combinations of parameters can be selected through different waveforms which are characteristic of each laser system. Hence, it is difficult to understand which one is preferable for welding and how similar weld shapes can be achieved when other variables such as welding speed, pulse repetition frequency, average power and beam diameter are applied. For example, Sun et al. [16] observed that penetration depth increased for higher pulse frequency, owing to increasing overlapping factor and average power. In their research study, the data analysis was done in terms of system parameters, which prevented a direct process comparison with different PW laser systems. Therefore, the underpinning laser-material interaction in terms of power density and energy needs to be understood and correlated with the weld bead profiles.

The laser user typically wants to control the depth of penetration, weld width and distortion, and avoid defect formation. The power factor model, previously developed for low carbon steel [25] and then extended for aluminium [26], can select the optimum laser parameter settings for laser power and welding speed for a given beam diameter, to obtain a specific weld profile in CW macro laser welding. This study focuses on redefining the original formula to fit the characteristics of PW lasers. This research aims to create an analytical model which allows the choice of pulse width, peak power, pulse energy, welding speed, pulse repetition frequency and beam diameter to obtain the depth of penetration and weld width suitable for micro-joining applications, transferrable between various laser systems. Due to the considerable number of parameters used throughout this work, a list of abbreviations is presented in Table 1.

\section{Mathematical formulation of the model}

\subsection{Definition of the fundamental laser-material in- teraction parameters}

The application of energy per unit length of the material is well defined for CW laser welding. However, the pulse shape can be electronically modulated in nanosecond pulsed lasers, as shown in Fig. 1. The power distribution is not constant during the entire duration of the pulse, the peak power being instantaneous. Consequently, the average peak power represents the average of the power distribution within a pulse, being lower than the peak power, but higher than the average power. The pulse energy is the integral of power over pulse duration, which can also be represented by the area in red of the pulse shape.

The weld profile can be described by the fundamental laser-material interaction parameters (FLMIP) in CW mode, which include average power density, specific pulse energy

Table 1 List of abbreviations

\begin{tabular}{lll}
\hline Abbreviation & Description & Units \\
\hline $\mathrm{P}_{\mathrm{L}}$ & Average output power & $\mathrm{W}$ \\
$\mathrm{v}$ & Welding speed & $\mathrm{mm} / \mathrm{s}$ \\
$\mathrm{d}$ & Beam diameter & $\mu \mathrm{m}$ \\
$\mathrm{A}_{\mathrm{S}}$ & Area of the laser beam size on the material & $\mathrm{mm}^{2}$ \\
& $\quad$ surface & $\mathrm{kHz}$ \\
$\mathrm{PRF}$ & Pulse repetition frequency & $\mathrm{ms}$ \\
$\mathrm{t}_{\mathrm{i}}$ & Interaction time & $\mathrm{kW}$ \\
$\mathrm{P}_{\text {peak }}$ & Average peak power & $\mathrm{mJ}$ \\
$\mathrm{E}_{\text {pulse }}$ & Pulse energy & $\mathrm{ns}$ \\
$\mathrm{P}_{\mathrm{Width}}$ & Pulse width & $\mathrm{MW} / \mathrm{cm}^{2}$ \\
$\mathrm{q}_{\mathrm{p}}$ & Average power density & $\mathrm{MW} / \mathrm{cm}^{2}$ \\
$\mathrm{q}_{\mathrm{p}, \text { peak }}$ & Average peak power density & $\mathrm{mJ}$ \\
$\mathrm{E}_{\mathrm{SP}, \text { pulse }}$ & Specific pulse energy & $\%$ \\
DC & Duty cycle & $\%$ \\
$\mathrm{O}_{\mathrm{F}}$ & Overlap factor & $\mathrm{MW} / \mathrm{m}$ \\
$\mathrm{P}_{\mathrm{F}, \text { pulse }}$ & Pulse power factor &
\end{tabular}


Fig. 1 Differentiation of lasers in terms of temporal outputs in continuous wave and modulated pulsed wave modes
CW operation

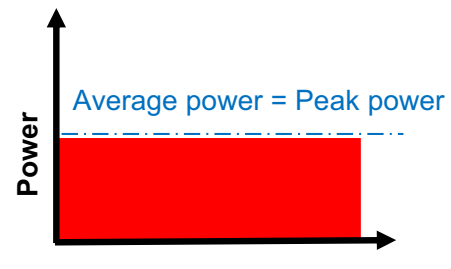

Time
Modulated PW operation

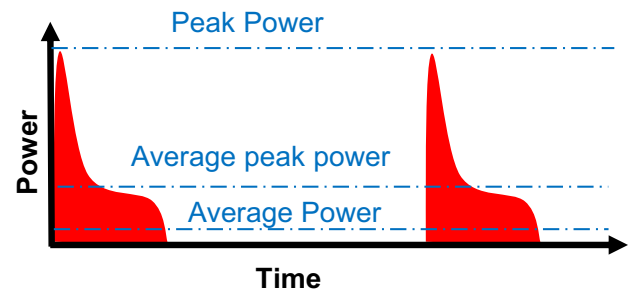

and interaction time [27]. However, in PW processing, the same parameters can be applied with various temporal characteristics, such as overlap factor $\left(O_{F}\right)$, pulse energy $\left(E_{\text {pulse }}\right)$, average peak power $\left(P_{\text {peak }}\right)$, pulse duration $\left(P_{\text {width }}\right)$ and pulse repetition frequency $(P R F)$. Therefore, a new set of parameters is proposed and studied in this work for PW mode.

Several PRF can be selected for each waveform. According to Fig. 2, there is a specific frequency $\left(P R F_{0}\right)$ at which the laser operates with the highest pulse energy for a particular waveform. Below $P R F_{0}$, the pulse energy remains constant, but the average power reduces proportionally to the frequency reduction. Above $P R F_{0}$, the pulse energy decreases when the frequency increases [14], as given by Eq. (1). Since the peak power of each pulse is only instantaneous over the pulse duration, similarly to previous studies [28, 29], this work has also considered the average peak power over the entire pulse duration for the calculation of the pulse energy in Eq. (2).

$E_{\text {pulse }}=P_{L} / P R F[\mathrm{~J}]$

$P_{\text {peak }}=E_{\text {pulse }} / P_{\text {width }}[\mathrm{W}]$

The overlap factor $\left(O_{F}\right)$ represents the percentage of overlap between the consecutive spots, which is dependent on the welding speed $(v)$, beam diameter $(d)$ and $P R F$, as given by Eq. (3) [30]:

$O_{F}=(1-v / d P R F) 100[\%]$

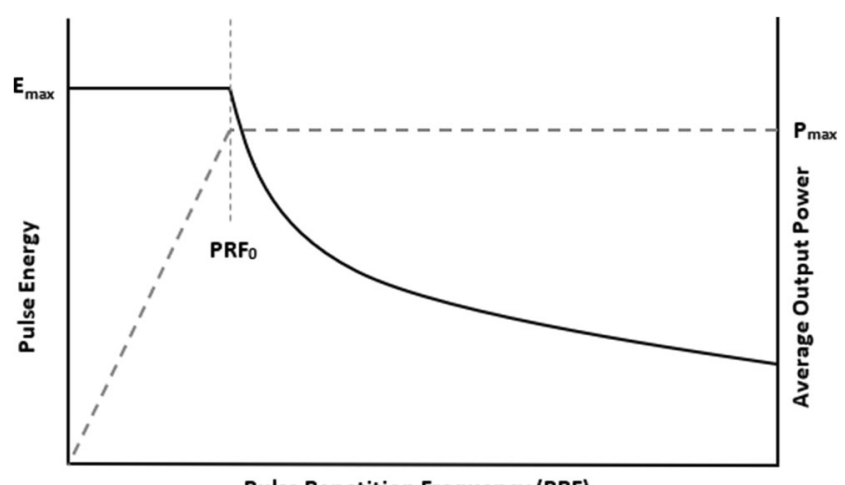

Fig. 2 Output characterization of the nanosecond PW laser [29]
Interaction time $\left(t_{i}\right)$ defines the time in which a point is exposed to the laser beam in the weld centreline. Therefore, in PW mode, it is dependent on the duration of each pulse $\left(P_{\text {width }}\right)$ and the overlap between them, as given by Eq. (4). At $0 \%$ overlap factor, the interaction time is equal to pulse duration and at $100 \%$, the equation is not applicable, since the beam is stationary. Hence, Eq. (4) is only applicable below $100 \%$ of overlapping factor $[28,29]$.

$t_{i}=\left(P_{\text {Width }} /\left(1-O_{F} / 100\right)\right)[\mathrm{ms}]$

The average power density $\left(q_{p}\right)$ is defined as the ratio of the average output power $\left(P_{L}\right)$ to the area of the laser beam size on the surface $\left(A_{S}\right)$, which for a circular beam diameter is given by Eq. (5) [27]:

$q_{p}=P_{L} / A_{S}\left[\mathrm{MW} / \mathrm{cm}^{2}\right]$

The average peak power density $\left(q_{p, \text { peak }}\right)$ in $\mathrm{PW}$ processing is defined as the ratio of the average peak power by the area of the laser spot, as given by Eq. (6) [14]:

$q_{p, p e a k}=P_{\text {peak }} / A_{S}\left[\mathrm{MW} / \mathrm{cm}^{2}\right]$

The energy delivered to any specific point on the weld centreline is defined as the specific point energy $\left(E_{S P}\right)$. This definition was created for $\mathrm{CW}$ mode as the product of average power density, interaction time and the area of the laser spot on the surface [27]. However, due to the peak power effect on the weld shape for constant average power in PW mode [28, 29], the definition has been reformulated to specific pulse energy $\left(E_{S P, \text { pulse }}\right)$, as given by Eq. (7):

$E_{S P, p u l s e}=q_{p, \text { peak }} t_{i} A_{S}=P_{\text {peak }} t_{i}[\mathrm{~J}]$

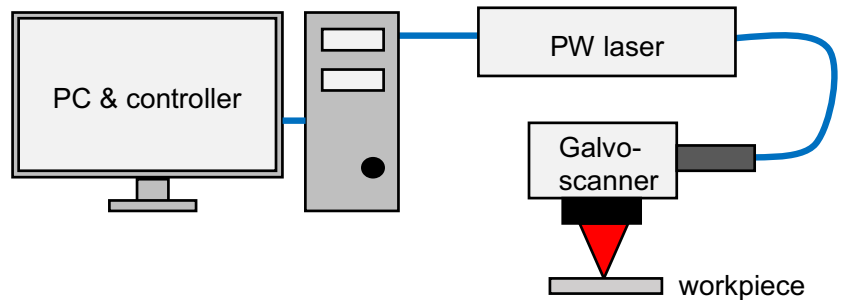

Fig. 3 Experimental setup of PW fibre laser used for stainless-steel welding 
Table 2 Chemical composition of the base materials [31]

\begin{tabular}{|c|c|c|c|c|c|c|c|c|c|c|c|c|c|c|}
\hline \multirow[t]{2}{*}{ Material } & \multicolumn{14}{|c|}{ Elements (wt\%) } \\
\hline & $\mathrm{Si}$ & $\mathrm{Fe}$ & $\mathrm{P}$ & $\mathrm{Cu}$ & $\mathrm{Mn}$ & $\mathrm{Mg}$ & $\mathrm{N}$ & $\mathrm{Ni}$ & $\mathrm{Zn}$ & $\mathrm{Ti}$ & $\mathrm{Cr}$ & $\mathrm{C}$ & $\mathrm{Al}$ & $\mathrm{Fe}$ \\
\hline $304 \mathrm{~L}$ & $\operatorname{Max} 1.00$ & Bal. & Max 0.05 & - & Max 2.00 & - & Max 0.11 & $8.0-11$ & - & - & $18-20$ & Max 0.03 & - & $\mathrm{Bal}$ \\
\hline
\end{tabular}

Table 3 Set of parameters used for a constant beam diameter of $89 \mu \mathrm{m}$, pulse width of $500 \mathrm{~ns}$ and average power of $100 \mathrm{~W}$

\begin{tabular}{|c|c|c|c|c|c|c|c|c|c|}
\hline $\begin{array}{l}\text { Average peak power } \\
\text { density }\left(\mathrm{MW} / \mathrm{cm}^{2}\right)\end{array}$ & $\begin{array}{l}\text { Specific pulse } \\
\text { energy }(\mathrm{mJ})\end{array}$ & $\begin{array}{l}\text { Average power } \\
\text { density }\left(\mathrm{MW} / \mathrm{cm}^{2}\right)\end{array}$ & $\begin{array}{l}\text { Interaction } \\
\text { time }(\mathrm{ms})\end{array}$ & $\begin{array}{l}\text { Welding } \\
\text { speed }(\mathrm{mm} / \\
\mathrm{s})\end{array}$ & $\begin{array}{l}\text { Frequency } \\
(\mathrm{kHz})\end{array}$ & $\begin{array}{l}\text { Pulse } \\
\text { energy } \\
(\mathrm{mJ})\end{array}$ & $\begin{array}{l}\text { Average peak } \\
\text { power }(\mathrm{kW})\end{array}$ & $\begin{array}{l}\text { Overlap } \\
\text { factor }(\%)\end{array}$ & $\begin{array}{l}\text { Duty } \\
\text { cycle } \\
(\%)\end{array}$ \\
\hline $\mathrm{q}_{\mathrm{p} \text {,peak }}$ & $\mathrm{E}_{\mathrm{SP}, \text { pulse }}$ & $\mathrm{q}_{\mathrm{p}}$ & $t_{i}$ & $\mathrm{v}$ & PRF & $E_{\text {pulse }}$ & $P_{\text {peak }}$ & $\mathrm{O}_{\mathrm{F}}$ & DC \\
\hline 8 & 25 & 1.6 & 0.05 & 356 & 400 & 0.25 & 0.5 & 99 & 20 \\
\hline 8 & 500 & 1.6 & 1 & 17.9 & 400 & 0.25 & 0.5 & 99.95 & 20 \\
\hline 8 & 2500 & 1.6 & 5 & 3.6 & 400 & 0.25 & 0.5 & 99.99 & 20 \\
\hline 8 & 125 & 1.6 & 0.250 & 71 & 400 & 0.25 & 0.5 & 99.8 & 20 \\
\hline 16 & 125 & 1.6 & 0.125 & 71 & 200 & 0.5 & 1 & 99.6 & 10 \\
\hline
\end{tabular}

\subsection{Definition of pulse power factor}

In CW laser welding, $q_{p}$ and $E_{S P}$ control the depth of penetration and are both dependent on the area of the laser beam, being possible to achieve similar penetration depth with a combination of high power density and low specific point energy or vice versa [27]. The first parameter is the inverse square of the beam diameter, whereas the second is linearly dependent on the beam diameter. From this relationship, it was found that the depth of penetration is proportional to the ratio of average power to beam diameter and a new parameter was established, the power factor. It has been shown that the penetration depth in CW keyhole regime can be approximated by the power factor model, which enables the achievement of a particular depth of penetration independent of the beam diameter selected [25]. However, as previously shown in Fig. 1, the average power is the same as peak power and they cannot be independently varied in CW mode. On the other hand, in PW mode, the peak power is higher than the average power and both parameters can be independently varied, which affects the final weld shape $[28,29]$. Hence, it is necessary to reformulate the definition of power factor for PW processing to take into consideration the effect of peak power in the weld shape when the average power is kept constant.

In this study, a new definition of power factor has been established and tested, the pulse power factor $\left(P_{F, \text { pulse }}\right)$, which can be defined as the ratio of average peak power by the beam diameter, as given by Eq. (8):

$P_{F, p u l s e}=P_{\text {peak }} / d[\mathrm{MW} / \mathrm{m}]$

\section{Experimental setup}

The welds were carried out in austenitic stainless steel $304 \mathrm{~L}$ with the following dimensions: $40 \times 70 \times 2 \mathrm{~mm}$ (Width $\mathrm{x}$ Length $x$ Depth). The chemical composition of this alloy is shown in Table 2.

The experimental setup is shown in Fig. 3. A TRUMPF G4 nanosecond pulsed wave (Z-type) with an average output power of $100 \mathrm{~W}$, maximum peak power of $10 \mathrm{~kW}$, maximum pulse energy of $1 \mathrm{~mJ}$ and maximum pulse duration of $500 \mathrm{~ns}$ was used in these experiments. The temporal response of the
Table 4 Characteristics of waveform 31 of PW laser

\begin{tabular}{|c|c|c|c|c|}
\hline Waveform & Pulse width (ns) & $\begin{array}{l}\text { Pulse repetition } \\
\text { frequency }(\mathrm{kHz})\end{array}$ & $\begin{array}{l}\text { Max pulse energy, } \\
\text { Emax }(\mathrm{mJ})\end{array}$ & $\begin{array}{l}\text { Peak power } \\
\text { at Emax }(\mathrm{kW})\end{array}$ \\
\hline wfm & $\mathrm{P}_{\text {width }}$ & PRF0 & $\mathrm{E}_{\text {pulse }}$ & - \\
\hline 31 & 500 & 100 & 1 & 7 \\
\hline
\end{tabular}


Table 5 Set of parameters used for different beam diameters at constant pulse width of $500 \mathrm{~ns}$ and average power of $100 \mathrm{~W}$

\begin{tabular}{|c|c|c|c|c|c|c|c|c|c|c|}
\hline $\begin{array}{l}\text { Beam } \\
\text { diameter } \\
(\mu \mathrm{m})\end{array}$ & $\begin{array}{l}\text { Frequency } \\
(\mathrm{kHz})\end{array}$ & $\begin{array}{l}\text { Welding } \\
\text { speed } \\
(\mathrm{mm} / \mathrm{s})\end{array}$ & $\begin{array}{l}\text { Pulse } \\
\text { energy } \\
(\mathrm{mJ})\end{array}$ & $\begin{array}{l}\text { Average } \\
\text { peak power } \\
(\mathrm{kW})\end{array}$ & $\begin{array}{l}\text { Overlap } \\
\text { factor } \\
(\%)\end{array}$ & $\begin{array}{l}\text { Duty } \\
\text { cycle } \\
(\%)\end{array}$ & $\begin{array}{l}\text { Interaction } \\
\text { time }(\mathrm{ms})\end{array}$ & $\begin{array}{l}\text { Average power } \\
\text { density (MW/ } \\
\mathrm{cm}^{2} \text { ) }\end{array}$ & $\begin{array}{l}\text { Average peak } \\
\text { power density } \\
\left(\mathrm{MW} / \mathrm{cm}^{2}\right)\end{array}$ & $\begin{array}{l}\text { Specific } \\
\text { pulse energy } \\
(\mathrm{mJ})\end{array}$ \\
\hline$d$ & PRF & $\mathrm{v}$ & $E_{\text {Pulse }}$ & $P_{\text {peak }}$ & $\mathrm{O}_{\mathrm{F}}$ & $\mathrm{DC}$ & $t_{i}$ & $\mathrm{q}_{\mathrm{p}}$ & $\mathrm{q}_{\mathrm{p} \text {, peak }}$ & $E_{S P, \text { pulse }}$ \\
\hline 35 & 255 & 89 & 0.39 & 0.78 & 99 & 12.75 & 0.05 & 10.4 & 81 & 39 \\
\hline 59 & 151 & 89 & 0.66 & 1.3 & 99 & 7.6 & 0.05 & 3.70 & 48 & 66 \\
\hline 89 & 100 & 89 & 1.0 & 2.0 & 99 & 5 & 0.05 & 1.60 & 32 & 100 \\
\hline 35 & 255 & 18 & 0.39 & 0.78 & 99.8 & 12.75 & 0.25 & 10.4 & 81 & 195 \\
\hline 59 & 151 & 18 & 0.66 & 1.3 & 99.8 & 7.6 & 0.25 & 3.70 & 48 & 330 \\
\hline 89 & 100 & 18 & 1.0 & 2.0 & 99.8 & 5 & 0.25 & 1.60 & 32 & 500 \\
\hline 35 & 255 & 9 & 0.39 & 0.78 & 99.9 & 12.75 & 0.5 & 10.4 & 81 & 390 \\
\hline 59 & 151 & 9 & 0.66 & 1.3 & 99.9 & 7.6 & 0.5 & 3.70 & 48 & 660 \\
\hline 89 & 100 & 9 & 1.0 & 2.0 & 99.9 & 5 & 0.5 & 1.60 & 32 & 1000 \\
\hline
\end{tabular}

Table 6 Set of system parameters used for different combinations of pulse power factor and interaction time at constant average power of $100 \mathrm{~W}$ and pulse width of $500 \mathrm{~ns}$

\begin{tabular}{|c|c|c|c|c|c|c|c|c|}
\hline $\begin{array}{l}\text { Pulse } \\
\text { power } \\
\text { factor } \\
(\mathrm{MW} / \mathrm{m})\end{array}$ & $\begin{array}{l}\text { Interaction } \\
\text { time (ms) }\end{array}$ & $\begin{array}{l}\text { Beam } \\
\text { diameter } \\
(\mu \mathrm{m})\end{array}$ & $\begin{array}{l}\text { Frequency } \\
(\mathrm{kHz})\end{array}$ & $\begin{array}{l}\text { Welding } \\
\text { speed } \\
(\mathrm{mm} / \mathrm{s})\end{array}$ & $\begin{array}{l}\text { Pulse } \\
\text { energy } \\
(\mathrm{mJ})\end{array}$ & $\begin{array}{l}\text { Average } \\
\text { peak } \\
\text { power } \\
(\mathrm{kW})\end{array}$ & $\begin{array}{l}\text { Overlap } \\
\text { factor } \\
(\%)\end{array}$ & $\begin{array}{l}\text { Duty } \\
\text { cycle } \\
(\%)\end{array}$ \\
\hline$P_{F}$, pulse & $\mathrm{t}_{\mathrm{i}}$ & d & PRF & $\mathrm{v}$ & $\mathrm{E}_{\text {Pulse }}$ & $P_{\text {peak }}$ & $\mathrm{O}_{\mathrm{F}}$ & $\mathrm{DC}$ \\
\hline $11.4-57$ & $0.05-5$ & 35 & $100-510$ & $1.8-1755$ & $0.2-1$ & $0.4-2.0$ & $99-99.99$ & $5-25$ \\
\hline $6.8-33.6$ & $0.05-5$ & 59 & $100-510$ & $1.8-2975$ & $0.2-1$ & $0.4-2.0$ & $99-99.99$ & $5-25$ \\
\hline $4.5-22.5$ & $0.05-5$ & 89 & $100-510$ & $1.8-4450$ & $0.2-1$ & $0.4-2.0$ & $99-99.99$ & $5-25$ \\
\hline
\end{tabular}

laser radiation was measured using a high-speed photodetector (MenloSystems) connected to an oscilloscope (Tektronix) with $1 \mathrm{GHz}$ bandwidth and a sampling capacity of 5 Giga samples per second (Gs/s). The laser beam was delivered through an optical fibre of $50-\mu \mathrm{m}$ diameter connected to a galvo-scanner (RAYLASE Superscan) equipped with f-theta focusing lens with a focal length of $160 \mathrm{~mm}$. An air knife was used with compressed gas to protect the lens from spatter and no shielding gas was applied on the substrate. The optical properties of the laser, such as beam diameter, focus position and depth of focus, were measured using a DataRay slit-scan beam profiler. The laser output power was measured by a Laserpoint power meter.
The samples were mechanically ground, polished and electrolytically etched with $10 \%$ of oxalic acid. Micrographs were taken with an Optiphot optical microscope with several magnifications. The weld width and depth of penetration were measured using a Carl Zeiss Axio Vision 4.8 image analysis software (https://www.zeiss.com/microscopy/int/products/ microscopesoftware/axiovision.html). The experimental error was calculated based on the difference of the penetration depth measured between the first and second cross sections for the same welding parameters. The welds with an experimental error above $20 \%$ were excluded from this analysis.
Table 7 Set of FLMIP used for different combinations of pulse power factor, interaction time and beam diameter at constant average power of $100 \mathrm{~W}$ and pulse width of $500 \mathrm{~ns}$

\begin{tabular}{llllll}
\hline $\begin{array}{l}\text { Pulse power } \\
\text { factor }(\mathrm{MW} / \mathrm{m})\end{array}$ & $\begin{array}{l}\text { Interaction } \\
\text { time }(\mathrm{ms})\end{array}$ & $\begin{array}{l}\text { Beam } \\
\text { diameter } \\
(\mu \mathrm{m})\end{array}$ & $\begin{array}{l}\text { Average power } \\
\text { density }\left(\mathrm{MW} / \mathrm{cm}^{2}\right)\end{array}$ & $\begin{array}{l}\text { Average peak power } \\
\text { density }\left(\mathrm{MW} / \mathrm{cm}^{2}\right)\end{array}$ & $\begin{array}{l}\text { Specific pulse } \\
\text { energy }(\mathrm{mJ})\end{array}$ \\
\hline $\mathrm{P}_{\mathrm{F}, \text { pulse }}$ & $\mathrm{t}_{\mathrm{i}}$ & $\mathrm{d}$ & $\mathrm{q}_{\mathrm{p}}$ & $\mathrm{q}_{\mathrm{p}, \text { peak }}$ & $\mathrm{E}_{\mathrm{SP}, \text { pulse }}$ \\
$11.4-57$ & $0.05-5$ & 35 & 10.4 & $41-208$ & $2-2000$ \\
$6.8-33.6$ & $0.05-5$ & 59 & 3.70 & $14-72$ & $2-3500$ \\
$4.5-22.5$ & $0.05-5$ & 89 & 1.60 & $6-32$ & $2-10,000$ \\
\hline
\end{tabular}


Table 8 Properties of waveforms 0,27 and 31 at $\mathrm{PRF}_{0}$ and maximum average power of 100 W

\begin{tabular}{lllll}
\hline Waveform & Pulse width (ns) & $\begin{array}{l}\text { Pulse repetition } \\
\text { frequency }(\mathrm{kHz})\end{array}$ & $\begin{array}{l}\text { Max pulse energy, } \\
\text { Emax }(\mathrm{mJ})\end{array}$ & $\begin{array}{l}\text { Peak Power } \\
\text { at Emax }(\mathrm{kW})\end{array}$ \\
\hline $\mathrm{wfm}$ & $\mathrm{P}_{\text {Width }}$ & $\mathrm{PRF}_{0}$ & $\mathrm{E}_{\text {pulse }}$ & - \\
0 & 280 & 100 & 1 & 10 \\
27 & 350 & 100 & 1 & 7 \\
31 & 500 & 100 & 1 & 7 \\
\hline
\end{tabular}

Table 9 Set of system parameters for different combinations of pulse power factor and interaction time applied in waveforms 0,27 and 31 at constant beam diameter of $35 \mu \mathrm{m}$ and average power of $100 \mathrm{~W}$

\begin{tabular}{|c|c|c|c|c|c|c|c|c|c|}
\hline $\begin{array}{l}\text { Pulse power factor } \\
(\mathrm{MW} / \mathrm{m})\end{array}$ & $\begin{array}{l}\text { Interaction } \\
\text { time (ms) }\end{array}$ & Waveform & $\begin{array}{l}\text { Pulse } \\
\text { width (ns) }\end{array}$ & $\begin{array}{l}\text { Welding speed } \\
(\mathrm{mm} / \mathrm{s})\end{array}$ & $\begin{array}{l}\text { Frequency } \\
(\mathrm{kHz})\end{array}$ & $\begin{array}{l}\text { Pulse } \\
\text { energy }(\mathrm{mJ})\end{array}$ & $\begin{array}{l}\text { Average peak } \\
\text { power }(\mathrm{kW})\end{array}$ & $\begin{array}{l}\text { Duty } \\
\text { cycle (\%) }\end{array}$ & $\begin{array}{l}\text { Overlap } \\
\text { factor }(\%)\end{array}$ \\
\hline $\mathrm{P}_{\mathrm{F}, \text { pulse }}$ & $t_{i}$ & wfm & $P_{\text {Width }}$ & $\mathrm{v}$ & PRF & $E_{\text {pulse }}$ & $P_{\text {peak }}$ & DC & $\mathrm{O}_{\mathrm{F}}$ \\
\hline 102 & 0.056 & 0 & 280 & 17.5 & 100 & 1.0 & 3.6 & 2.8 & 99.50 \\
\hline 81.6 & 0.070 & 27 & 350 & 17.5 & 100 & 1.0 & 2.9 & 3.5 & 99.50 \\
\hline 57.1 & 0.10 & 31 & 500 & 17.5 & 100 & 1.0 & 2.0 & 5.0 & 99.5 \\
\hline 57.1 & 0.10 & 0 & 280 & 17.5 & 179 & 0.56 & 2.0 & 5.0 & 99.72 \\
\hline 57.1 & 0.10 & 27 & 350 & 17.5 & 143 & 0.70 & 2.0 & 5.0 & 99.65 \\
\hline 57.1 & 0.10 & 31 & 500 & 17.5 & 100 & 1.0 & 2.0 & 5.0 & 99.50 \\
\hline 28.6 & 0.10 & 0 & 280 & 35.0 & 357 & 0.28 & 1.0 & 10.0 & 99.72 \\
\hline
\end{tabular}

\section{Methodology}

\subsection{Experimental study rationale}

It is known that in $\mathrm{CW}$ laser welding, the weld shape is controlled by both average power density and applied energy. High power density and high applied energy guarantee high vaporisation rate, and consequently, high aspect-ratio welds, whereas long laser-material interaction time creates large weld pools [27]. A specific penetration depth can be achieved through a trade-off between both parameters, which is the working base of the power factor model in CW mode [26].

A similar approach used in $\mathrm{CW}$ mode has been tested in PW mode to control the weld shape through a new set of three proposed parameters. First, the average peak power density should control the transition from conduction to keyhole mode. High aspect-ratio welds may be possible to achieve when high average peak power densities are applied through small beam diameters and high average peak powers at low pulse repetition frequencies. Second, the specific pulse energy may also control the penetration depth. High applied energy may lead to more heat accumulation to generate sufficient molten metal. It can be achieved through large beam diameters and high energy per pulse at low frequencies. Third, the interaction time may control the weld width. Large melt pools may be characteristic of low welding speeds at high pulse repetition frequencies.

If the proposed new set of parameters controls the weld shape, the power factor model may also be applicable in PW mode. The common variables of average peak power
Table 10 Set of FLMIP for different combinations of pulse power factor and interaction time applied in waveforms 0,27 and 31 at constant beam diameter of $35 \mu \mathrm{m}$ and average power of 100 $\mathrm{W}$

\begin{tabular}{lllll}
\hline $\begin{array}{l}\text { Pulse power } \\
\text { factor }(\mathrm{MW} / \mathrm{m})\end{array}$ & $\begin{array}{l}\text { Interaction } \\
\text { time }(\mathrm{ms})\end{array}$ & $\begin{array}{l}\text { Average power } \\
\text { density }\left(\mathrm{MW} / \mathrm{cm}^{2}\right)\end{array}$ & $\begin{array}{l}\text { Average peak power } \\
\text { density }\left(\mathrm{MW} / \mathrm{cm}^{2}\right)\end{array}$ & $\begin{array}{l}\text { Specific pulse } \\
\text { energy }(\mathrm{mJ})\end{array}$ \\
\hline $\mathrm{P}_{\mathrm{F}, \text { pulse }}$ & $\mathrm{t}_{\mathrm{i}}$ & $\mathrm{q}_{\mathrm{p}}$ & $\mathrm{q}_{\mathrm{p}, \text { peak }}$ & $\mathrm{E}_{\mathrm{SP}, \text { peak }}$ \\
102 & 0.056 & 10.4 & 371 & 200 \\
81.6 & 0.070 & 10.4 & 297 & 200 \\
57.1 & 0.10 & 10.4 & 208 & 200 \\
57.1 & 0.10 & 10.4 & 208 & 200 \\
57.1 & 0.10 & 10.4 & 208 & 200 \\
57.1 & 0.10 & 10.4 & 208 & 200 \\
28.6 & 0.10 & 10.4 & 104 & 100 \\
\hline
\end{tabular}


Fig. 4 Micrographs of bead-onplate welds made at different average peak power densities, similar average power density of 1.6 $\mathrm{MW} / \mathrm{cm}^{2}$ and specific pulse energy of $125 \mathrm{~mJ}$

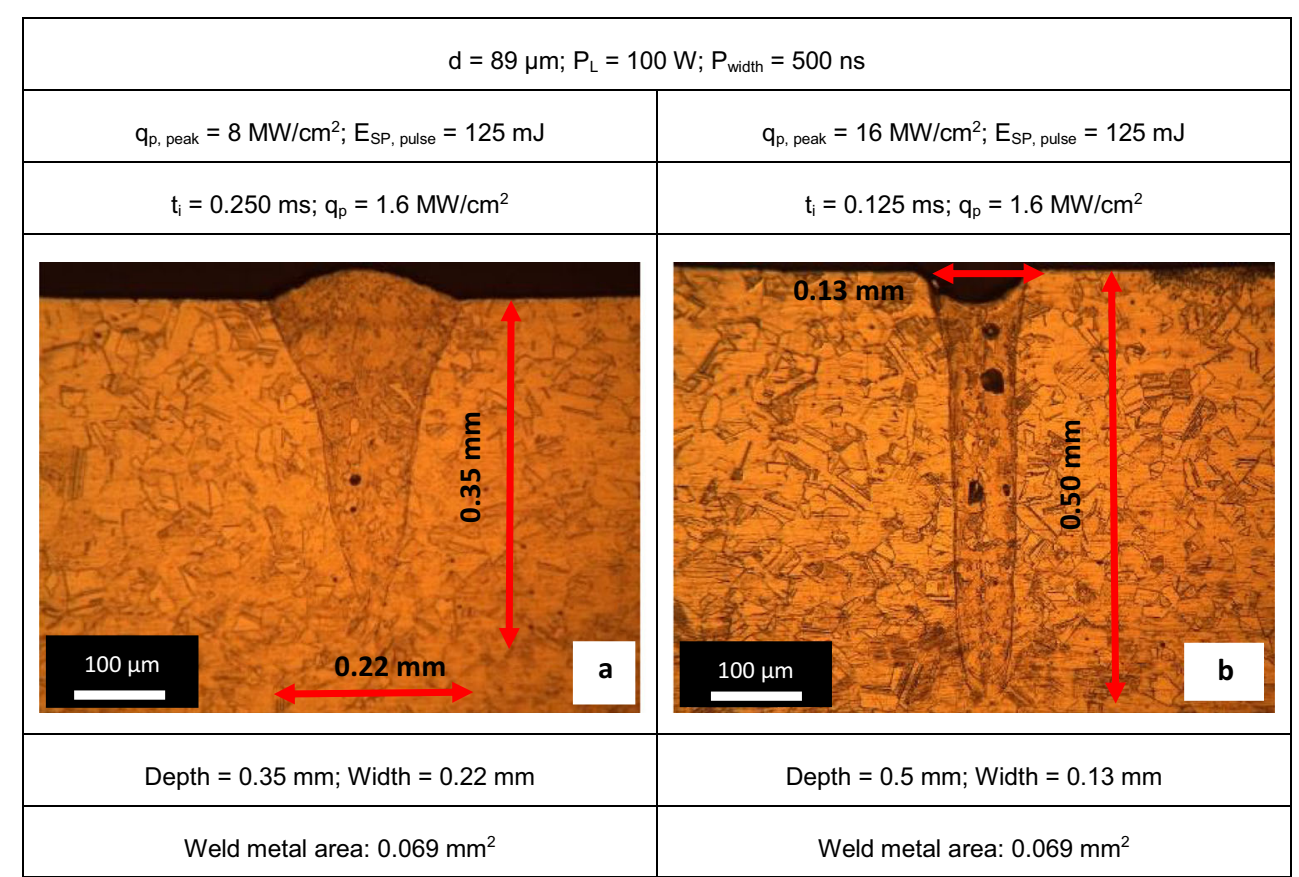

density, specific pulse energy and interaction time are the beam diameter and the pulse repetition frequency. Therefore, the foundation of the pulse power factor model is built on the relationship between both: The combination of small beam diameters and low pulse repetition frequencies will lead to high values of pulse power factors and short interaction times. Consequently, a high vaporisation rate and high aspect-ratio welds may be achieved until a certain threshold to avoid drilling the material. On the other hand, large beam diameters and high pulse repetition frequencies will lead to low pulse power factor values and long interaction times, which may create enough heat accumulation to generate large weld pools, more suitable for applications where high fit-up tolerance is required. In both cases, similar penetration depths may be reached for different trade-offs between pulse power factor and

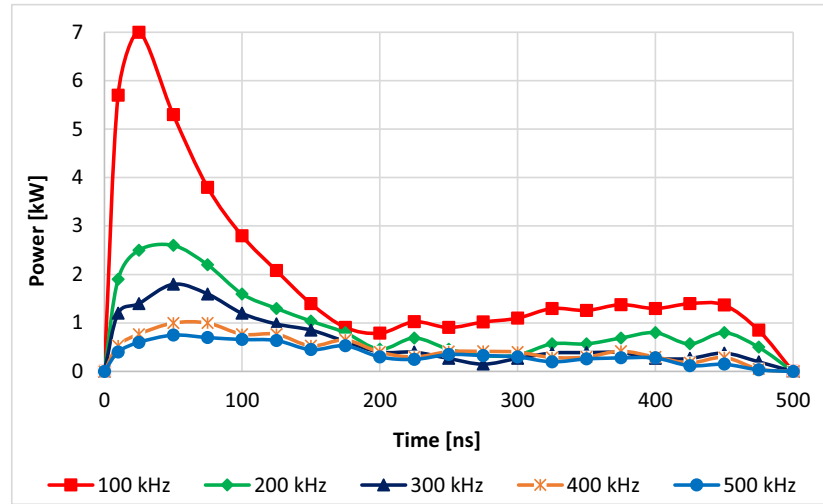

Fig. 5 Pulse shapes of waveform 31 (pulse width of $500 \mathrm{~ns}$ ) for different pulse repetition frequencies at constant average power of $100 \mathrm{~W}$ interaction time, independently of the beam diameter and frequency selected.

The average laser output power was kept constant in this study. Therefore, the average power density can be disregarded from the analysis of the results. The laser temporal pulse shape selected dictates the maximum peak power and energy per pulse possible to achieve. Its effect on the material response was investigated for different pulse repetition frequencies and correlated with the model only in the last section.

\subsection{Effect of average peak power density and specific pulse energy}

This section investigates the effect of the proposed new set of parameters in the penetration depth of PW bead-on-plate welds using a fixed beam diameter, average power and pulse width. The joint effect of $E_{\text {pulse }}, P_{\text {peak }}, v$ and $P R F$ was described by $q_{p \text {, peak }}$ and $E_{S P, \text { pulse. }}$. In the first stage, $q_{p \text {, peak }}$

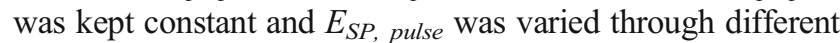
$v$, constant $P R F, E_{\text {pulse }}$ and $P_{\text {peak }}$. In the second stage, $E_{S P, \text { pulse }}$ was kept constant and $q_{p \text {, peak }}$ was varied through different $P R F, E_{\text {pulse }}$ and $P_{\text {peak }}$ and a constant $v$. The set of parameters studied are shown in Table 3. The characteristics of the temporal pulse shape used are shown in Table 4.

\subsection{Effect of beam diameter}

To explore the applicability of the new parameters in different laser systems, a set of bead-on-plate welds with different beam diameters of $0.35,0.59$ and $0.89 \mu \mathrm{m}$, 


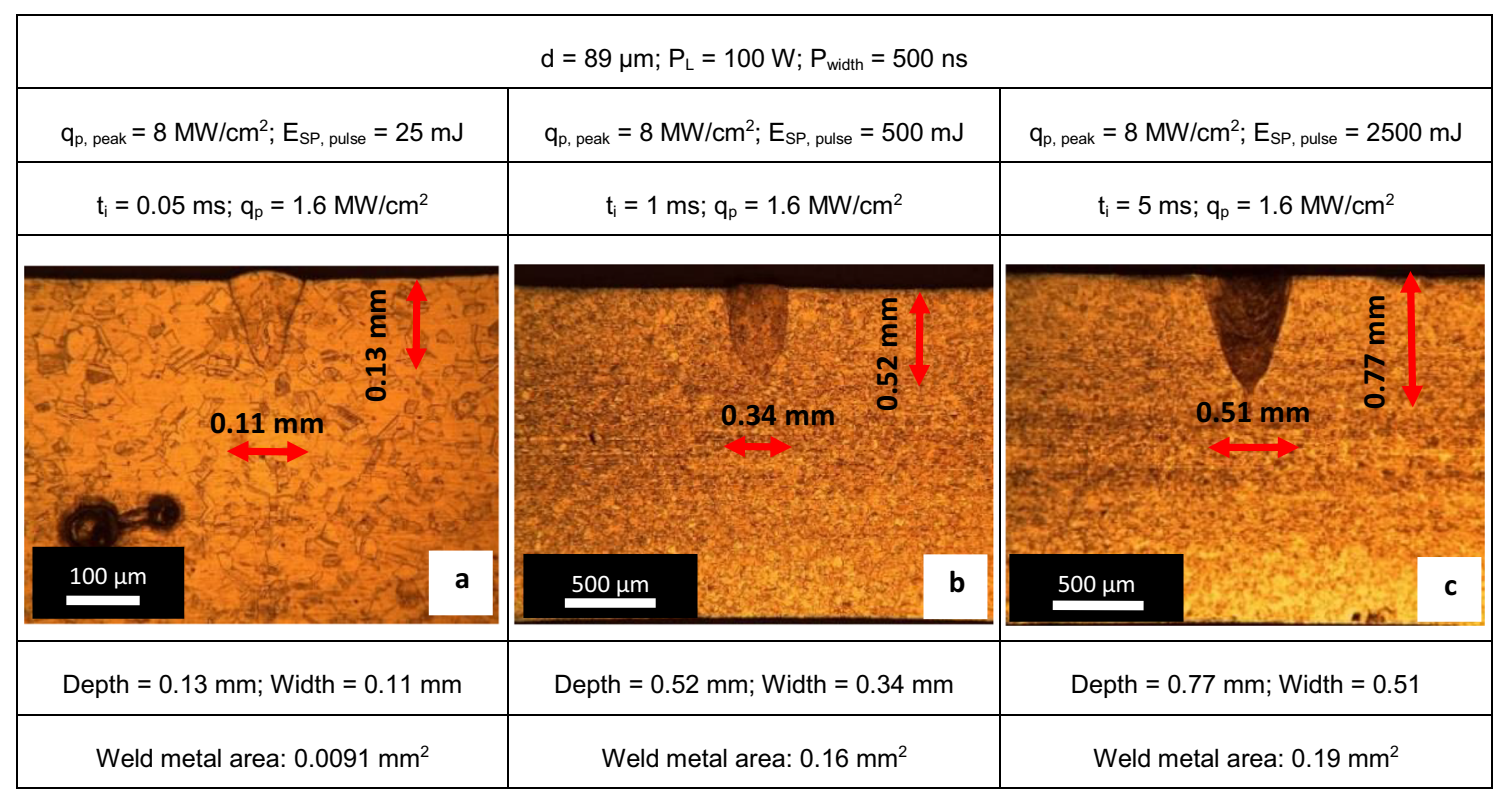

Fig. 6 Micrographs of bead-on-plate welds at different specific pulse energy, similar average peak power density of $8 \mathrm{MW} / \mathrm{cm}^{2}$ and average power of 1.6 $\mathrm{MW} / \mathrm{cm}^{2}$

constant average power and pulse width were used. For each beam diameter, different combinations of $P_{\text {peak }}$, $E_{\text {pulse }}, v$ and $P R F$ were used, resulting in a range of $q_{p}$ from 1.60 to $10.4 \mathrm{MW} / \mathrm{cm}^{2}, q_{p \text {, peak }}$ from 32 to $81 \mathrm{MW} /$ $\mathrm{cm}^{2}$ and $E_{S P}$, pulse from $39 \mathrm{~mJ}$ to $1000 \mathrm{~J}$. Since in CW mode it is possible to achieve the same penetration depth with high $q_{p}$ and low $E_{S P}$ or vice versa [27], this section intends to prove that the same dependence is also valid for PW mode when different beam diameters are applied. The set of parameters used is shown in Table 5.

\subsection{Effect of pulse power factor and interaction time}

The pulse power factor model was tested using a set of bead-on-plate welds achieved with different beam

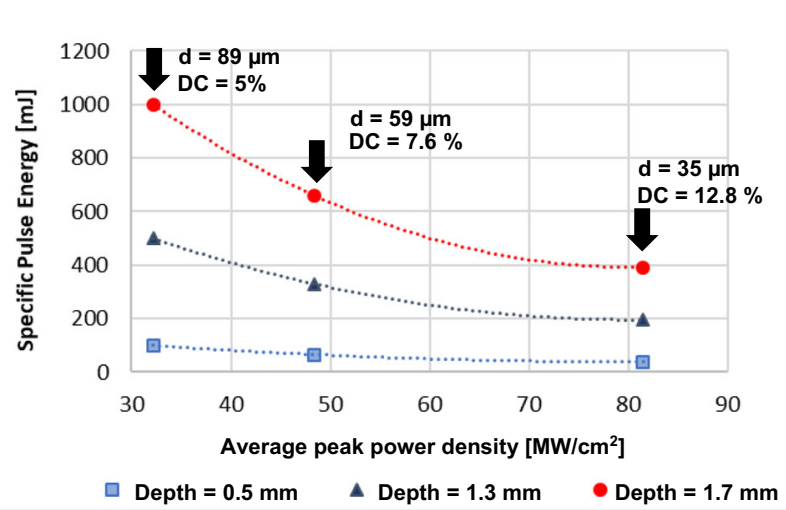

Fig. 7 Specific pulse energy versus average peak power density for depths of penetration of $0.5,1.3$ and $1.7 \mathrm{~mm}$ at a constant average power of $100 \mathrm{~W}$ and pulse width of $500 \mathrm{~ns}$ diameters of $0.35,0.59$ and $0.89 \mu \mathrm{m}$, constant average power and constant pulse width. The effect on the penetration depth and weld width was investigated in two stages: First, for each beam diameter, different combinations of $P_{F}$, pulse and $t_{i}$ were used by varying $P_{\text {peak }}, E_{\text {pulse }}$, $v$ and $P R F$. These combinations of system parameters resulted in a range of $P_{F, \text { pulse }}$ from 4.5 to $57 \mathrm{MW} / \mathrm{m}$ and $t_{i}$ from 0.05 and $5 \mathrm{~ms}$. The penetration depths and weld widths were analysed for each combination and only four penetration depths $(0.3,0.7,1.0$ and $1.4 \mathrm{~mm})$ were considered to simplify the representation of the results. In the second stage, to prove that similar weld shapes can be achieved independently of the beam diameter selected (35-89 $\mu \mathrm{m})$, for each beam diameter, constant values of $P_{F, p u l s e}$ of 22.4 and $11.2 \mathrm{MW} / \mathrm{m}$ were used for similar values of $t_{i}$, ranging from 0.05 to $0.5 \mathrm{~ms}$. The processing parameters are shown in Tables 6 and Table 7.

\subsection{Effect of temporal pulse shape}

This laser system allows the selection of thirty-one different waveforms [32]. Each waveform is characterised by a specific peak power, $E_{\text {pulse }}$ and $P_{\text {Width }}$ and can be operated for a wide range of $v$ and $P R F$. This section investigates the applicability of the pulse power factor model in controlling the weld shape when different laser temporal pulse shapes are used. A set of bead-on-plate welds with several combinations of $P_{F \text {, pulse }}$ and $t_{i}$ were applied in waveforms 0,27 and 31 at constant beam diameter and average power. The intrinsic properties of each waveform are shown in Table 8 and the set of parameters used are shown in Tables 9 and 10. 


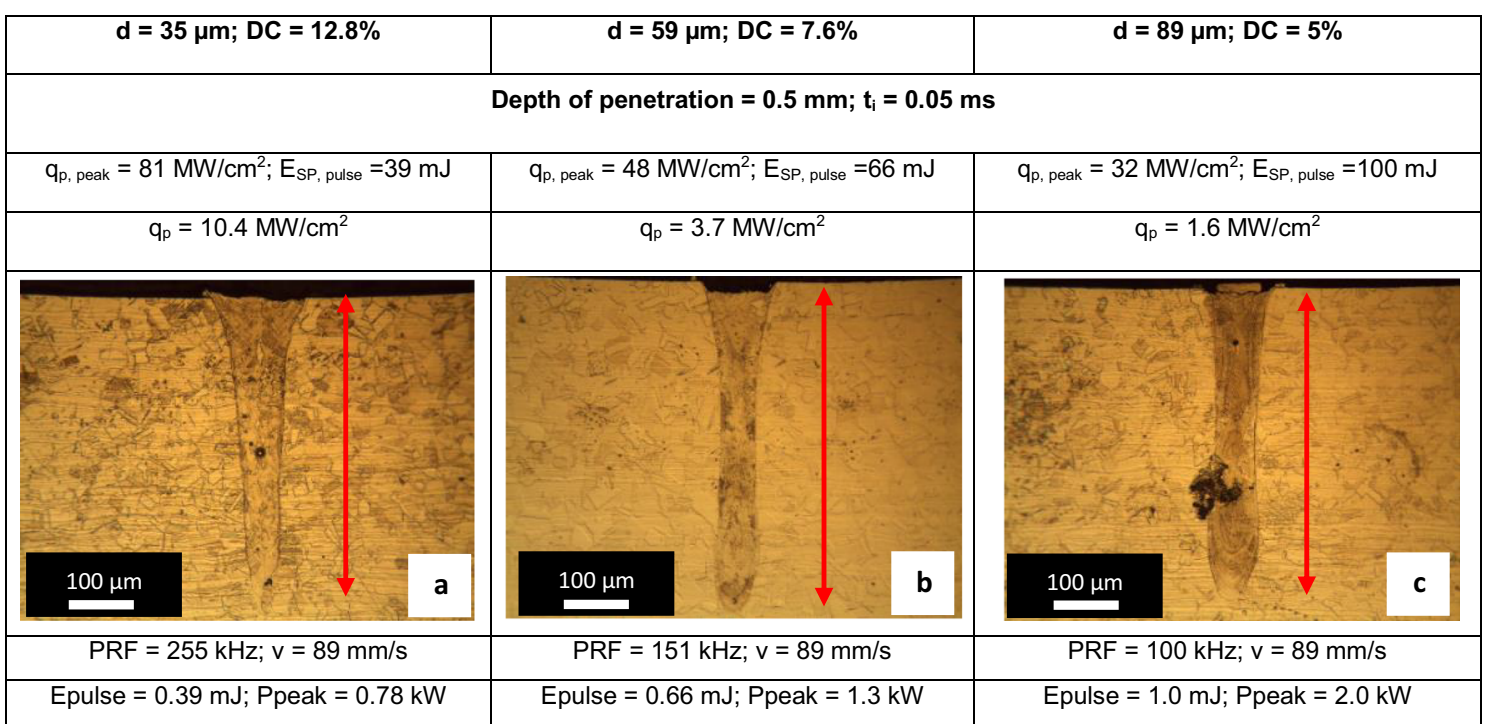

Fig. 8 Different combinations of average power density, average peak power density and specific pulse energy for a constant weld depth of $0.5 \mathrm{~mm}$

\section{Results and discussion}

\subsection{Effect of average peak power density and specific pulse energy}

The effect of $q_{p \text {, peak }}$ on the weld shape for constant $q_{p}$ and $E_{S P}$, pulse is shown in Fig. 4. From Fig. 4a-b, the penetration depth increased from 0.35 to $0.50 \mathrm{~mm}$ by doubling $q_{p}$, pulse from 8 to $16 \mathrm{MW} / \mathrm{cm}^{2}$ at constant $q_{p}$ of $1.6 \mathrm{MW} / \mathrm{cm}^{2}$ and $E_{S P, \text { pulse }}$ of $125 \mathrm{~mJ}$. The reduction of frequency at constant welding speed, beam diameter and pulse width led to a reduction of the overlap between pulses (Table 3), which resulted in fewer pulses applied per unit length and consequently, a reduction of $t_{i}$ from $0.250 \mathrm{~ms}$ in Fig. $4 \mathrm{a}$ to $0.125 \mathrm{~ms}$ in Fig. 4b. However, as shown in the temporal response of the laser in Fig. 5, when the frequency decreases, the pulse shape changes and $E_{\text {pulse }}$ and $P_{\text {peak }}$ increase. Even though the average power is constant $(100 \mathrm{~W})$, an increase in $P_{\text {peak }}$ is crucial to increase the material

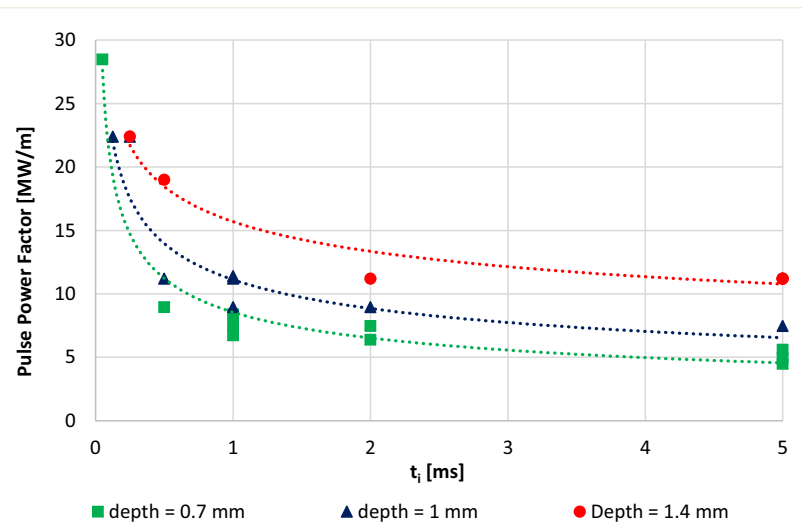

Fig. 9 Pulse power factor for depths of penetration of $0.3,0.7,1$ and $1.4 \mathrm{~mm}$ as a function of interaction time for beam diameters of 35,59 and $89 \mu \mathrm{m}$ vaporisation rate through a higher $q_{p, \text { pulse, }}$ which created a higher penetration depth in Fig. $4 \mathrm{~b}$ in comparison to Fig. 4a. Thus, it is possible to conclude that $\mathrm{q}_{\mathrm{p} \text {, peak }}$ controls the penetration depth in pulsed wave micro-seam welding for constant $q_{p}$ and $E_{S P, \text { pulse. }}$.

The effect of $E_{S P, \text { pulse }}$ on the weld shape for a constant $q_{p}$ and $q_{p, \text { pulse }}$ is shown in Fig. 6. From Fig. 6a-c, the penetration depth increased by increasing $E_{S P, \text { pulse }}$ at constant $q_{p}$ of 1.6 $\mathrm{MW} / \mathrm{cm}^{2}$ and $q_{p \text {, peak }}$ of $8 \mathrm{MW} / \mathrm{cm}^{2}$. Due to an increase of overlap between pulses at constant $P R F$ and beam diameter, the welding speed decreased (Table 3 ), which is reflected in an increase in the number of pulses applied per unit length and a consequent increase of the laser-material interaction time from 0.05 in Fig. 6a to $5 \mathrm{~ms}$ in Fig. 6c. Consequently, the total energy delivered to the laser spot increased in the same ratio, from 25 to $2500 \mathrm{~mJ}$, and the heat transfer rate from the hot surface to the cold bottom was much higher, being enough to build up the temperature of the material to a such level where a keyhole was formed. It can be concluded that $E_{S P \text {, pulse }}$ controls the penetration depth in pulsed wave micro-seam welding for constant $q_{p}$ and $q_{p, \text { peak }}$.

\subsection{Effect of beam diameter}

The previous section showed that the penetration depth can be independently controlled by $q_{p \text {, peak }}$ and $E_{S P}$, pulse when $q_{p}$ is kept constant by using constant beam diameter and average power. This section investigates the correlation between $q_{p}$, peak and $E_{S P}$, pulse and its effect on the penetration depth when different beam diameters of 35, 59 and $89 \mu \mathrm{m}$ and constant average power of $100 \mathrm{~W}$ are used.

From a wide range of experiments, a few different cases with the same penetration depth were selected and plotted as a function of $E_{S P \text {, pulse }}$ and $q_{p, \text { peak }}$, as shown in Fig. 7. The trend 


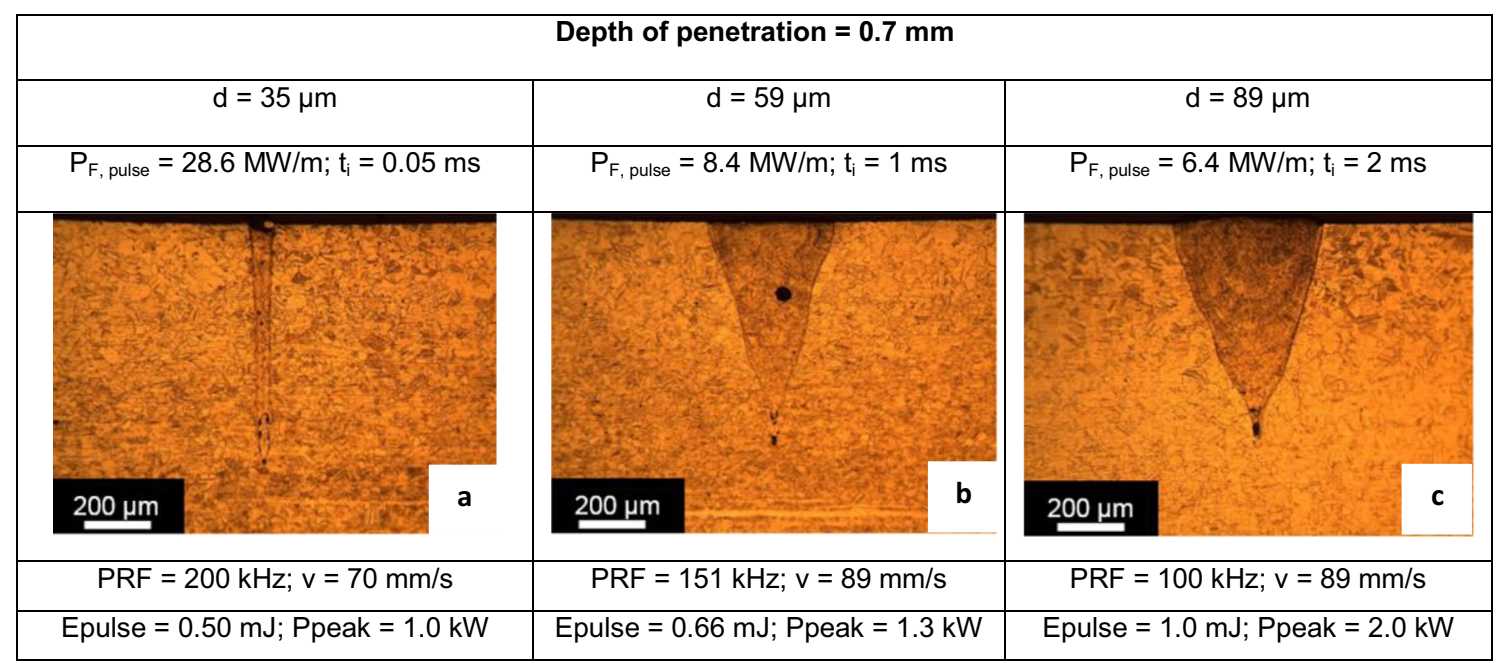

Fig. 10 Constant depth of penetration of $0.7 \mathrm{~mm}$ achieved with different combinations of pulse power factor and interaction time for beam diameters of $35 \mu \mathrm{m}, 59 \mu \mathrm{m}$ and $89 \mu \mathrm{m}$

line corresponds to constant penetration depths from 0.5 to 1.7 $\mathrm{mm}$. The $q_{p \text {, peak }}$ needed to achieve a particular penetration decreases quadratically with $E_{S P}$, pulse. This means that similarly to CW welding [26], there is also a trade-off between both parameters through a constant rate of material vaporisation [33] in PW micro-seam welding. Since both $t_{i}$ and $q_{p}$ have a direct influence on the maximum temperature of the thermal cycle [34], when $E_{S P, \text { pulse }}$ increases through an increase in $t_{i}$ for a constant $q_{p \text {, peak }}$ (Eq. (7)), the material experiences a peak in temperature for a longer period, increasing the penetration depth as well.

The corresponding micrographs from Fig. 7 are shown in Fig. 8 for a constant penetration depth of $0.5 \mathrm{~mm}$. The duty cycle also needs to be considered in the trade-off between $E_{S P}$, pulse and $q_{p \text {, peak }}$ from Fig. 8a-c. When the beam diameter increases, the duty cycle of the laser decreases to balance the reduction in $q_{p \text {, peak }}$ with an increase in $E_{S P \text {, pulse }}$ in the same proportion. For higher duty cycles, the substrate is subjected to high thermal load since the period between pulses is shorter [35]. Consequently, there is a reduction of energy loss

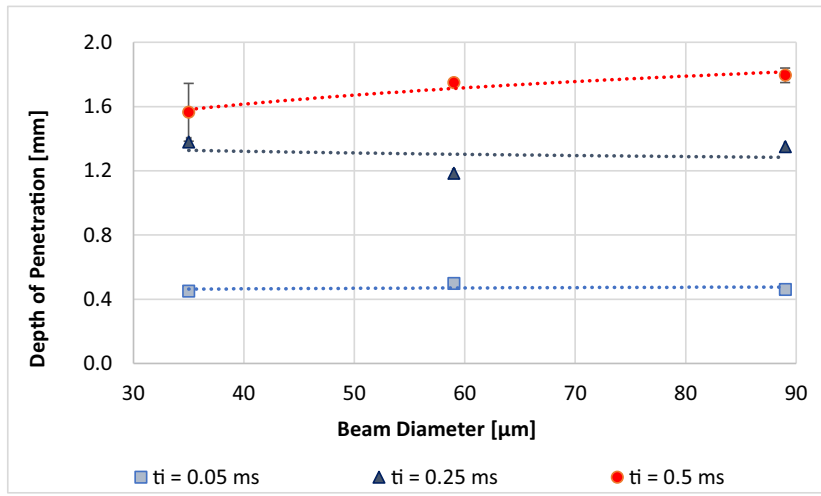

Fig. 11 Effect of the beam diameter on the depth of penetration at different interaction times and a constant pulse power factor of 22.4 $\mathrm{MW} / \mathrm{m}$ between pulses, keeping the penetration depth constant. This is even more evident when the pulse overlapping is high, creating a cumulative energy effect of the laser radiation through several pulses [14].

\subsection{Effect of pulse power factor and interaction time for PW welding}

As previously shown in Section 5.2, it is possible to achieve constant penetration depth with different beam diameters by varying processing parameters in such a controlled way to reach a particular combination of $q_{p \text {, peak }}$ and $E_{S P}$, pulse. The problem with such an approach is that both parameters are dependent on beam diameter and pulse repetition frequency. This can be simplified to a single parameter, the pulse power factor. An example of random data plotted as a function of $P_{F}$, pulse is shown in Fig. 9. Constant penetration depth curves can be obtained for different combinations of $t_{i}$ and $P_{F, \text { pulse }}$, being the weld width proportional to $t_{i}$.

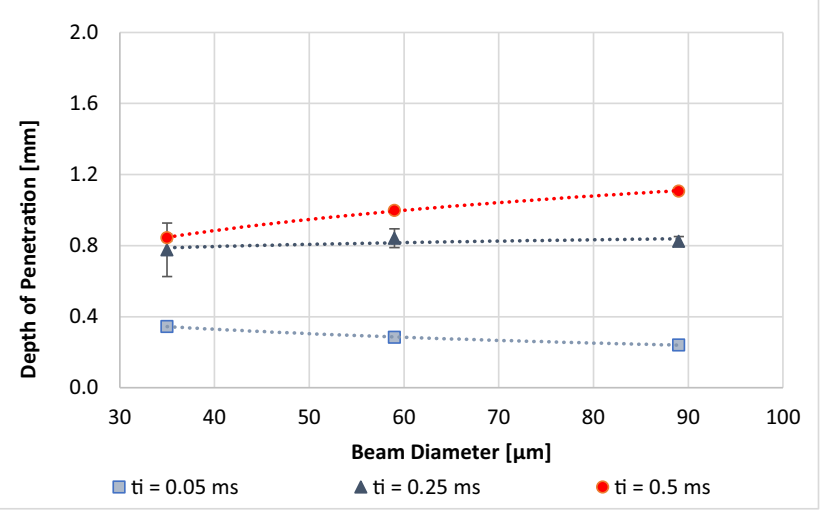

Fig. 12 Effect of the beam diameter on the depth of penetration at different interaction times and a constant pulse power factor of 11.2 $\mathrm{MW} / \mathrm{m}$ 


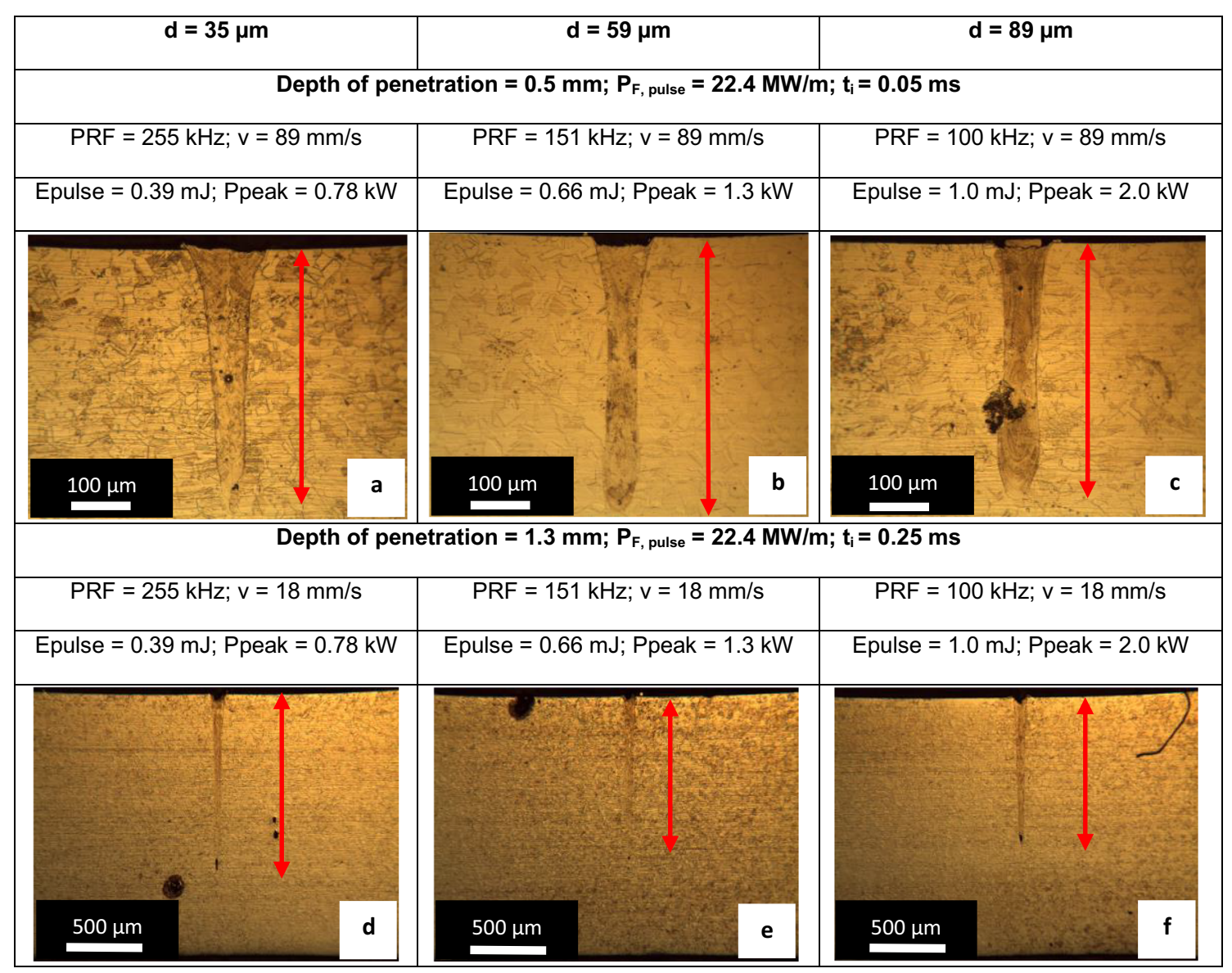

Fig. 13 Constant combinations of pulse power factor of $22.4 \mathrm{MW} / \mathrm{m}$ and interaction times of $0.05 \mathrm{~ms}$ and $0.25 \mathrm{~ms}$ for different beam diameters of 35,59 and $89 \mu \mathrm{m}$

Three micrographs were taken from the constant trend line of a penetration depth of $0.7 \mathrm{~mm}$ from Fig. 9 and presented in Fig. 10. At short $t_{i}$ and high $P_{F \text {, pulse (Fig. 10a), spiky weld }}$ profiles are achieved, which is a characteristic of a short interaction between the laser and the material, leading to rapid keyhole development and solidification. Short $t_{i}$ can either be achieved by fast welding speed, low overlapping factor or short pulse duration. Long $t_{i}$ and low $P_{F, \text { pulse }}$ (Fig. 10c), on the other hand, resulted in a wide weld profile similar to $\mathrm{CW}$ welding. Note that long $t_{i}$ can be achieved by a high overlapping factor. Eventually, the weld profile will approach a typical CW weld profile with a further increase of $t_{i}$. However, this model is not necessarily a good theory, especially for the same penetration depth due to fit-up problems [5]. Similar trend lines observed in PW micro-seam welding in Fig. 9 using the new definition of power factor (Eq. (8)) have also been demonstrated in $\mathrm{CW}$ macro welding of low carbon steel [25] and aluminium [26] using the standard definition of the model.

In Figs. 11 and 12, depth of penetration is presented as a function of $P_{F}$, pulse and $t_{i}$ using different beam diameters. Constant penetration is demonstrated for constant $t_{i}$ but only for certain spot sizes. For a beam diameter of $35 \mu \mathrm{m}$ at $t_{i}$ of 0.5 $\mathrm{ms}$, there is a higher variation in the depth of penetration when compared to larger beams of 59 and $89 \mu \mathrm{m}$.

The weld profiles from Figs. 11 and 12 are shown in Figs. 13 and 14. Comparing Fig. 13a-c with Fig. 13d-f, the penetration depth increased at constant $P_{F, \text { pulse }}$ since $t_{i}$ increased from 0.05 to $0.25 \mathrm{~ms}$. In Fig. 14, on the other hand, the reduction of $P_{F}$, pulse from 22.4 to $11.2 \mathrm{MW} / \mathrm{m}$ at a constant $t_{i}$ of $0.05 \mathrm{~ms}$ led to a reduction in the penetration depth. The variation of $P_{F}$, pulse at constant $t_{i}$ and beam diameter influenced the penetration depth and the weld width, since $P R F$ increased to compensate $E_{\text {pulse }}$ and $P_{\text {peak }}$ reduction. Consequently, it is likely the reduction of the laser's drilling force, being the energy delivered through more pulses, enlarging the weld pool. Therefore, constant $P_{F}$, pulse applied with a small beam diameter and high $P R F$ does not have the same effect on the weld width as the combination of a larger beam and lower PRF.

In Figs. 11 and 12, despite the increase in interaction time from 0.25 to $0.5 \mathrm{~ms}$ at constant $P_{F}$, pulse and constant beam diameter of $35 \mu \mathrm{m}$, the penetration depth remained almost unchanged, which shows the limitation of the model in small beam diameters. However, this limitation is also visible for larger beam diameters from a certain $t_{i}$ threshold, as shown 


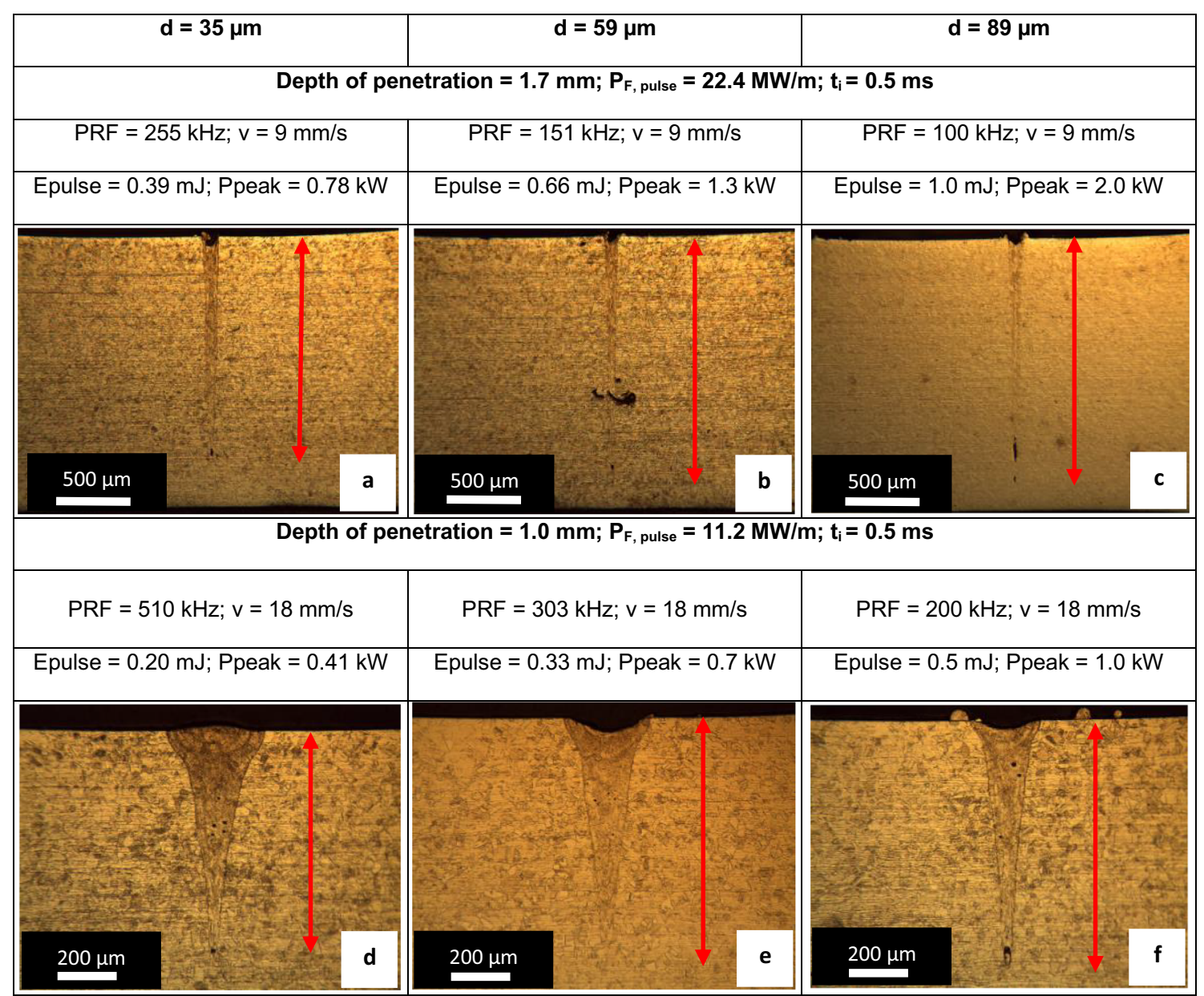

Fig. 14 Constant combinations of pulse power factors of $22.4 \mathrm{MW} / \mathrm{m}$ and $11.2 \mathrm{MW} / \mathrm{ms}$ and interaction time of $0.5 \mathrm{~ms}$ for different beam diameters of 35,59 and $89 \mu \mathrm{m}$

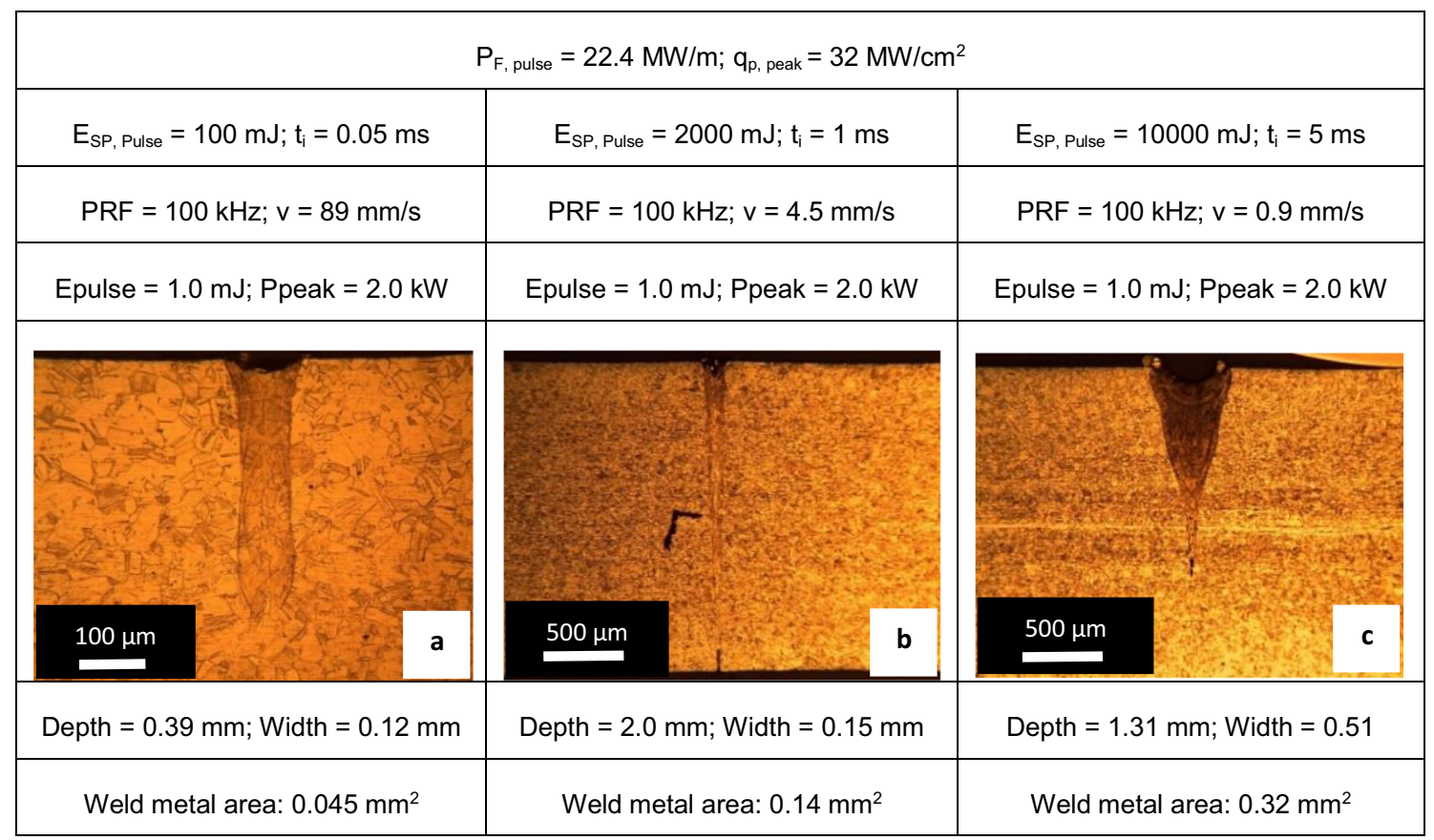

Fig. 15 Bead-on-plate welds at different interaction times, constant pulse power factor of $22.4 \mathrm{MW} / \mathrm{m}$, pulse duration of $500 \mathrm{~ns}$, beam diameter of 89 $\mu \mathrm{m}$, an average power of $100 \mathrm{~W}$ and duty cycle of $5 \%$ 


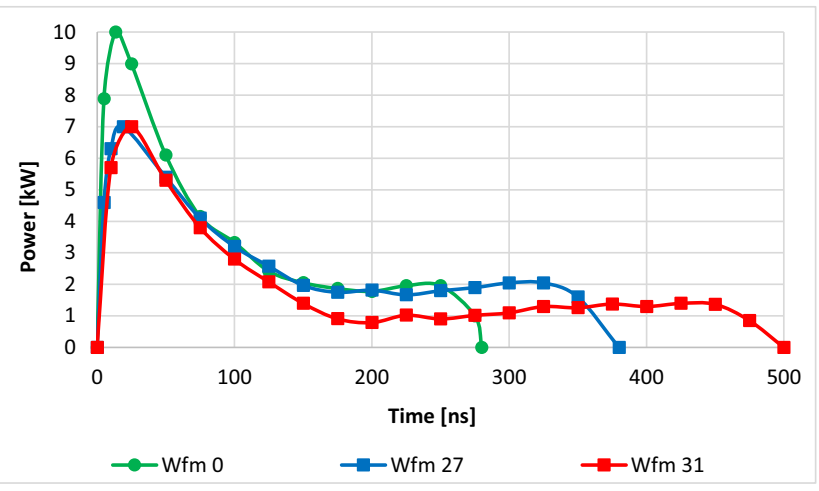

Fig. 16 Pulse shapes of waveform 0, 27 and 31 for a pulse repetition frequency of $100 \mathrm{kHz}$ at an average power of $100 \mathrm{~W}$

in Fig. 15. For a beam diameter of $89 \mu \mathrm{m}$ and constant $P_{F \text {, pulse }}$ of $22.4 \mathrm{MW} / \mathrm{m}$, the penetration depth increases until a $t_{i}$ of $1 \mathrm{~ms}$ (Fig. 15b) and then drops. The energy delivered in Fig. $15 \mathrm{c}$ for a $t_{i}$ of $5 \mathrm{~ms}$ is extremely high, being the thermal losses also higher for a constant average peak power which is not able to create more material vaporisation, leading to a reduction in penetration depth. Thus, it can be concluded that, in pulsed wave welding, higher $t_{i}$ and consequently higher $E_{S P \text {, }}$ pulse give the necessary cumulative heating effect to generate more material melting and increase the penetration depth, counteracting the high energy dissipation between pulses that the small heat source is subjected in comparison to the bulk material [14]. However, there is a limit in the trade-off between $q_{p \text {, peak }}$ and $E_{S P \text {, pulse }}$ to increase the penetration depth for a certain beam diameter and this limit is reached sooner for smaller beam diameters. Similar results were observed in laser machining using a similar nanosecond pulsed laser where the ablation rate increased with the power density until a certain point and then dropped from a certain limit [14]. The limit of this trade-off can be translated in the combination of maximum allowed $t_{i}$ for a maximum $P_{F}$, pulse. Therefore, in this study, for the range of beam diameters tested from 35 to 89 $\mu \mathrm{m}$, similar penetration depths can only be guaranteed until the combination of a maximum $t_{i}$ of $0.25 \mathrm{~ms}$ and a maximum $P_{F, \text { pulse }}$ of $22.4 \mathrm{MW} / \mathrm{m}$, as previously shown in Fig. 11.

\subsection{Effect of temporal pulse shape}

In the previous sections, the pulse power factor model was applied for a single pulse duration of $500 \mathrm{~ns}$. In this section, the model is used for different $P_{\text {Width }}$ of 280, 350 and $500 \mathrm{~ns}$ at a constant beam diameter of $35 \mu \mathrm{m}$ and average power of 100 $\mathrm{W}$. The correspondent laser temporal response was measured and shown in Fig. 16 for a constant PRF of $100 \mathrm{kHz}$. The highest peak power of $10 \mathrm{~kW}$ is achieved for the shortest pulse duration (wfm 0), whereas for longer pulses of $280 \mathrm{~ns}$ (wfm 27) and $500 \mathrm{~ns}$ (wfm 31), similar peak powers of $7 \mathrm{~kW}$ are achieved. However, at similar $P R F$, all waveforms have the same pulse energy (Table 8), but the longer the pulse duration, the higher the laser duty cycle.

In Fig. 17, a constant penetration depth of $1.3 \mathrm{~mm}$ was achieved independently of the waveform selected. For a short pulse duration, a high $P_{F \text {, pulse }}$ is necessary to compensate the low $t_{i}$ (Fig. 17a), whereas for longer pulses, a low $P_{F \text {, pulse }}$ is compensated by a high $t_{i}$ (Fig. 17c). From Fig. $17 \mathrm{a}-\mathrm{b}$, the $P_{\text {Width }}$ increased $1.25 \times$, from 280 to 350 ns. Consequently, the $P_{F}$, pulse was reduced $1.25 \times$, whereas $t_{i}$ was increased $1.25 \times$. From Fig. $17 \mathrm{a}-\mathrm{c}$, the $P_{\text {Width }}$ increased $1.8 \times$, from 280 to $500 \mathrm{~ns}$, and $P_{F}$, pulse and $t_{i}$ changed in the same proposition. In all cases, the penetration depth was kept constant since the

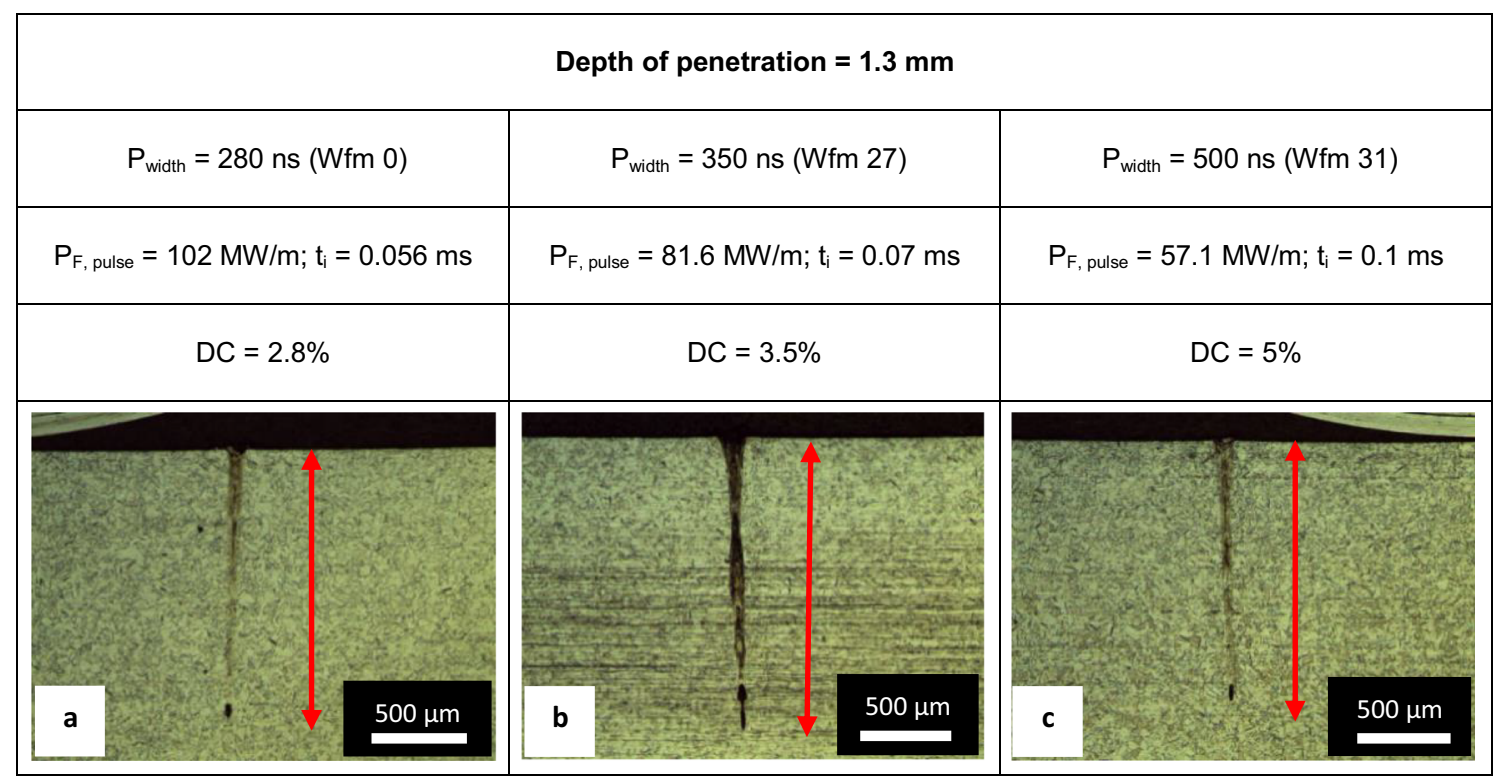

Fig. 17 Constant penetration depth of $1.3 \mathrm{~mm}$ achieved with different combinations of pulse power factors and interaction times in waveforms 0,27 and 31 at constant average power of $100 \mathrm{~W}$ and beam diameter of $35 \mu \mathrm{m}$ 
Fig. 18 Different penetration depths achieved in waveforms 0 and 31 for different pulse power factors and constant interaction time of $0.1 \mathrm{~ms}$, average power of $100 \mathrm{~W}$ and beam diameter of 35 $\mu \mathrm{m}$

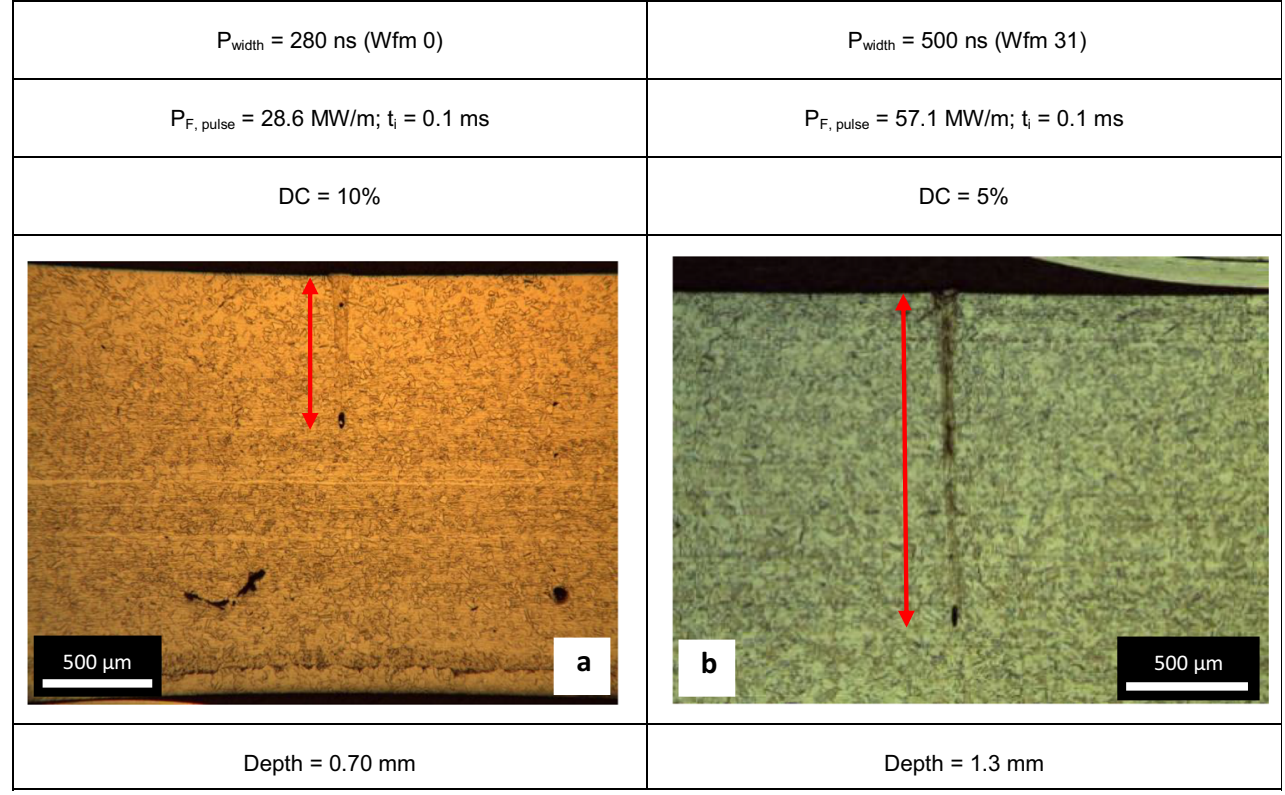

duty cycle of the laser compensated the difference in pulse duration and peak power verified in all waveforms in Fig. 16, allowing constant thermal losses between pulses. However, as observed in Fig. 18, if the duty cycle is not adjusted in the same proportion as $P_{\text {Width }}$, the pulse power factor model cannot be applied. From Fig. $18 \mathrm{a}-\mathrm{b}, P_{\text {Width }}$ increased $1.8 \times$ from 280 to $500 \mathrm{~ns}$, but the duty cycle was reduced to half, which resulted in a constant $t_{i}$, higher $P_{F}$, pulse and consequently, an increase in the penetration depth. Therefore, it can be concluded that the duty cycle is a critical parameter to consider in this model when different laser temporal modes are used.

There is an alternative to applying the model in different temporal pulse shapes. As observed in Fig. 19, a constant penetration depth of $1.3 \mathrm{~mm}$ was achieved in different waveforms for a constant $P_{F}$, pulse and $t_{i}$ due to a constant duty cycle of 5\%. According to Table 9, this was possible by adjusting $P R F$ to each $P_{\text {Width }}$. Hence, a constant combination of $q_{p}, q_{p}$, peak and $E_{S P}$, pulse was possible to achieve for the three different waveforms (Table 10). Consequently, the substrate was subjected to a constant thermal cycle since the period between successive pulses was constant, keeping the surface temperature and the penetration depth constant [35]. As previously concluded from Fig. 17 and confirmed once again in Fig. 19, the duty cycle is a critical parameter to consider in the pulse power factor model to achieve similar penetration depths in different waveforms. Similar results have been observed for laser scoring using a nanosecond pulsed laser [14], which means that the applicability of the pulse power factor model can be extended to other applications rather than just micro-joining.

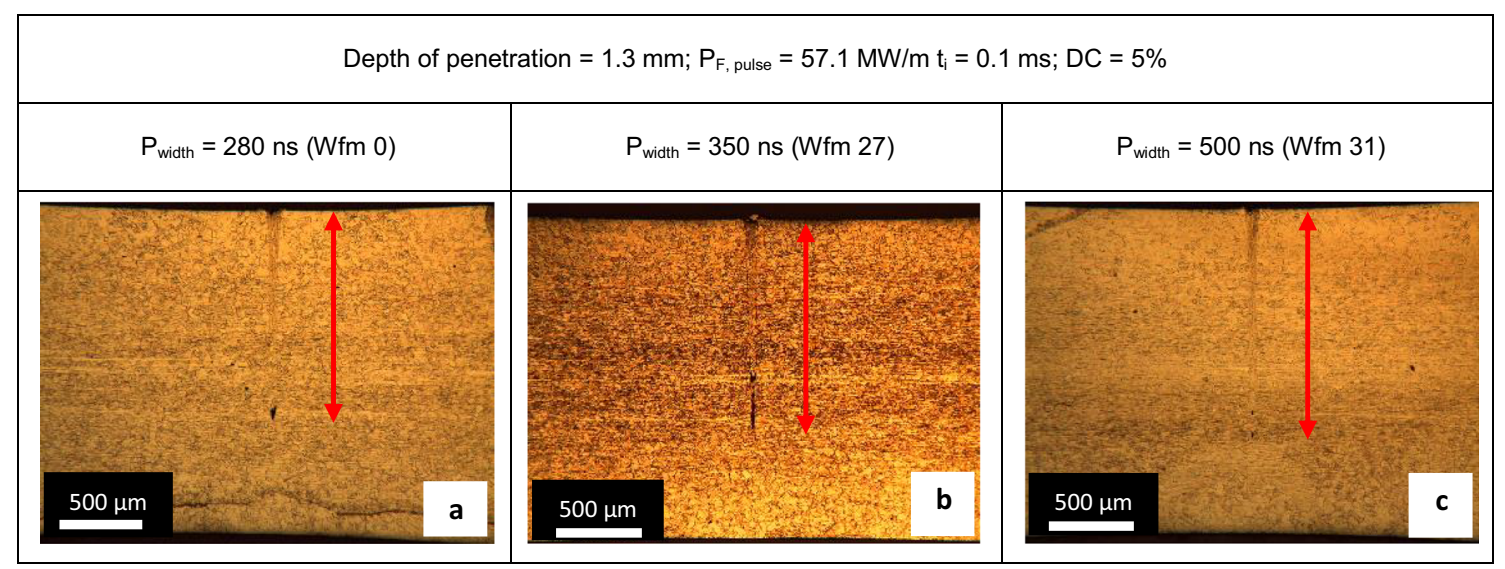

Fig. 19 Constant penetration depth of $1.3 \mathrm{~mm}$ achieved in waveforms 0,27 and 31 at a constant pulse power factor of $57.1 \mathrm{MW} / \mathrm{m}$, interaction time of $0.1 \mathrm{~ms}$, a duty cycle of $5 \%$, an average power of $100 \mathrm{~W}$ and beam diameter of $35 \mu \mathrm{m}$ 


\section{Conclusions}

The standard formulation of the power factor model in CW processing was redesigned and exploited in PW seam welding. The new definition, the pulse power factor, correlates the peak power rather than the average power with the beam diameter. The following conclusions have been taken:

- Average peak power density and specific pulse energy control the material vaporisation rate and heat accumulation, whereas the interaction time controls the weld width. The combination of these parameters simplifies the selection of pulse width, peak power, pulse energy, welding speed, pulse repetition frequency and beam diameter through the application of a new phenomenological model;

- The pulse power factor model allows the laser user to select a weld profile in stainless steel which meets certain quality and productivity requirements independent of the laser system: High aspect-ratio and productive welds can be achieved for high values of pulse power factor and short interaction times, whereas wider melt pools suitable for higher fit-up tolerance and less productive applications can be achieved for lower pulse power factors and longer interaction times;

- Constant penetration depth curves against interaction time and pulse power factor were achieved in stainless steel: A certain combination between high pulse power factor and short interaction time or vice versa will lead to similar penetration depths but different weld widths. The higher the penetration depth required, the higher the pulse power factor needed for similar interaction time;

- For each beam diameter, there is a threshold in the maximum interaction time for a certain pulse power factor, creating limitations on the applicability of the model due to unpredictable variations of the penetration depth. This limit is reached sooner for smaller beams than larger beams due to the difference in high energy losses caused by the ratio of the heat source to the bulk material;

- For a constant average power and beam diameter, the duty cycle is a critical parameter to calculate the pulse power factor and interaction time values needed to achieve similar weld shape in different laser temporal modes: For shorter pulse durations, the laser duty cycle is reduced to compensate in the same proportion the increase in peak power, keeping constant the trade-off between pulse power factor and interaction time.

- The high vaporisation rate applied through high peak power creates high aspect-ratio welds. This may be not suitable for other materials with different physical properties, such as melting point and thermal conductivity. For those circumstances, the model may show several limitations or may need to be optimised to guarantee a working envelope where the drilling regime is avoided and only melting in keyhole mode is possible.
Author contribution •Julio Coroado - PhD student. He has designed and produced the experimental work in consultation with the other co-authors and is the principal author of the manuscript.

-Supriyo Ganguly - reader. He helped in creation of research methodology and experimental work and provided the very essential research direction. Supriyo took active participation in preparing the manuscript.

-Stewart Williams - professor and chair of the Welding Engineering And Laser Processing Centre. He also participated actively in experimental design, data analysis and interpretation.

-Wojciech Suder - lecturer. As one of the laser experts, Wojciech provided important knowledge on the design of the experimental work and manuscript discussion.

-Sonia Meco - senior research fellow. Sonia participated in the manuscript checking and correction.

-Goncalo Pardal - senior research fellow. Goncalo also took active participation in data analysis, manuscript checking and correction.

Funding The researchers received funding support from Innovate UK (TS/MO11089/1) in the scope of the Environmental Domed End project.

Data availability Not applicable.

Code availability Not applicable.

\section{Declarations}

Ethical approval To the author's knowledge, this is the first paper showing how the penetration and weld width of stainless-steel resultant from the laser welding process is controlled by the pulse power factor and interaction time. The authors confirm that this manuscript has not been published elsewhere and is not under consideration by another journal.

Consent to participate Not applicable.

Consent for publication Not applicable.

Competing interests The authors declare no competing interests.

Open Access This article is licensed under a Creative Commons Attribution 4.0 International License, which permits use, sharing, adaptation, distribution and reproduction in any medium or format, as long as you give appropriate credit to the original author(s) and the source, provide a link to the Creative Commons licence, and indicate if changes were made. The images or other third party material in this article are included in the article's Creative Commons licence, unless indicated otherwise in a credit line to the material. If material is not included in the article's Creative Commons licence and your intended use is not permitted by statutory regulation or exceeds the permitted use, you will need to obtain permission directly from the copyright holder. To view a copy of this licence, visit http://creativecommons.org/licenses/by/4.0/.

\section{References}

1. Heise G, Heiss A, Vogt H, Huber HP (2012) Ultrafast lasers improve the efficiency of CIS thin film solar cells. Phys Procedia 39: 702-708. https://doi.org/10.1016/j.phpro.2012.10.091

2. Gu X, KaixuanZhu WS et al (2020) Effect of welding parameters on weld formation quality and tensile-shear property of laser welded SUS301L stainless steel lap filet weld. J Mater Res Technol 9:4840-4854. https://doi.org/10.1016/j.jmrt.2020. 03.004 
3. Hummel M, Schöler C, Häusler A, Gillner A, Poprawe R (2020) New approaches on laser micro welding of copper by using a laser beam source with a wavelength of $450 \mathrm{~nm}$. J Adv Join Process 1: 100012. https://doi.org/10.1016/j.jajp.2020.100012

4. Ramakrishna RVSM, Amrutha PHSLR, Rahman Rashid RA, Palanisamy S (2020) Narrow gap laser welding (NGLW) of structural steels - a technological review and future research recommendations. Int J Adv Manuf Technol 111:2277-2300

5. Errico V, Campanelli SL, Angelastro A, Mazzarisi M, Casalino G (2020) On the feasibility of AISI 304 stainless steel laser welding with metal powder. J Manuf Process 56:96-105. https://doi.org/10. 1016/j.jmapro.2020.04.065

6. Sozzi M, Tragni K, Selleri S et al (2013) Picosecond and nanosecond pulsed laser ablation of aluminium foil. In: ASME 2013 International Manufacturing Science and Engineering Conference Collocated with the 41st North American Manufacturing Research Conference, MSEC 2013

7. Chryssolouris G, Stavropoulos P, Salonitis K (2015) Process of laser machining. In: Nee AYC (ed) Handbook of manufacturing engineering and technology. Springer London, London, pp 16011628

8. Kuo TY, Lin HC (2006) Effects of pulse level of Nd-YAG laser on tensile properties and formability of laser weldments in automotive aluminum alloys. Mater Sci Eng A 416:281-289. https://doi.org/ 10.1016/j.msea.2005.10.041

9. Knebel T, Streek A, Exner H (2014) Comparison of high rate laser ablation and resulting structures using continuous and pulsed single mode fiber lasers. Phys Procedia 56:19-28. https://doi.org/10.1016/ j.phpro.2014.08.091

10. Williams E, Brousseau EB, Rees A (2014) Nanosecond Yb fibre laser milling of aluminium: effect of process parameters on the achievable surface finish and machining efficiency. Int J Adv Manuf Technol 74:769-780. https://doi.org/10.1007/s00170-0146038-6

11. Bluemel S, Jaeschke P, Suttmann O, Overmeyer L (2014) Comparative study of achievable quality cutting carbon fibre reinforced thermoplastics using continuous wave and pulsed laser sources. In: Physics Procedia

12. Wang XD, Michalowski A, Walter D, Sommer S, Kraus M, Liu JS, Dausinger F (2009) Laser drilling of stainless steel with nanosecond double-pulse. Opt Laser Technol 41:148-153. https://doi.org/10. 1016/j.optlastec.2008.05.021

13. Dumitru G, Lüscher B, Krack M, Bruneau S, Hermann J, Gerbig Y (2005) Laser processing of hardmetals: physical basics and applications. Int J Refract Met Hard Mater 23:278-286. https://doi.org/ 10.1016/j.jirmhm.2005.04.020

14. Banat D, Ganguly S, Meco S, Harrison P (2020) Application of high power pulsed nanosecond fibre lasers in processing ultra-thin aluminium foils. Opt Lasers Eng 129. https://doi.org/10.1016/j. optlaseng.2020.106075

15. Li JF, Sun YH, Ding DW, Wang WH, Bai HY (2020) Nanosecondpulsed laser welding of metallic glass. J Non-Cryst Solids 537: 120016. https://doi.org/10.1016/j.jnoncrysol.2020.120016

16. Sun Q, Di HS, Li JC, Wang XN (2016) Effect of pulse frequency on microstructure and properties of welded joints for dual phase steel by pulsed laser welding. Mater Des 105:201-211. https://doi.org/ 10.1016/j.matdes.2016.05.071

17. Sabbaghzadeh J, Hamedi MJ, Ghaini FM, Torkamany MJ (2008) Effect of process parameters on the melting ratio in overlap pulsed laser welding. Metall Mater Trans B Process Metall Mater Process Sci 39:340-347. https://doi.org/10.1007/s11663-008-9137-7

18. Kim J, Oh S, Ki H (2016) Effect of keyhole geometry and dynamics in zero-gap laser welding of zinc-coated steel sheets. J Mater
Process Technol 232:131-141. https://doi.org/10.1016/j. jmatprotec.2016.01.028

19. Kumar N, Mukherjee M, Bandyopadhyay A (2017) Study on laser welding of austenitic stainless steel by varying incident angle of pulsed laser beam. Opt Laser Technol 94:296-309. https://doi. org/10.1016/j.optlastec.2017.04.008

20. Zwicker MFR, Moghadam M, Zhang W, Nielsen CV (2020) Automotive battery pack manufacturing-a review of battery to tab joining. J Adv Join Process 1:100017. https://doi.org/10.1016/ j.jajp.2020.100017

21. Kuryntsev SV, Gilmutdinov AK (2015) Welding of stainless steel using defocused laser beam. J Constr Steel Res 114:305-313. https://doi.org/10.1016/j.jcsr.2015.08.004

22. Kumar P, Sinha AN (2018) Effect of pulse width in pulsed Nd: YAG dissimilar laser welding of austenitic stainless steel (304 L) and carbon steel (st37). Lasers Manuf Mater Process 5:317-334. https://doi.org/10.1007/s40516-018-0069-Z

23. Salonitis K, Stournaras A, Tsoukantas G, Stavropoulos P, Chryssolouris G (2007) A theoretical and experimental investigation on limitations of pulsed laser drilling. J Mater Process Technol 183:96-103. https://doi.org/10.1016/j.jmatprotec.2006.09.031

24. Jiang P, Wang C, Zhou Q, Shao X, Shu L, Li X (2016) Optimization of laser welding process parameters of stainless steel 316L using FEM, Kriging and NSGA-II. Adv Eng Softw 99:147160. https://doi.org/10.1016/j.advengsoft.2016.06.006

25. Suder WJ, Williams S (2014) Power factor model for selection of welding parameters in CW laser welding. Opt Laser Technol 56: 223-229. https://doi.org/10.1016/j.optlastec.2013.08.016

26. Coroado J, Meco S, Williams S, Ganguly S, Suder W, Quintino L, Assunção E (2017) Fundamental understanding of the interaction of continuous wave laser with aluminium. 93:3165-3174. https://doi. org/10.1007/s00170-017-0702-6

27. Suder WJ, Williams SW (2012) Investigation of the effects of basic laser material interaction parameters in laser welding. J Laser Appl 24:032009. https://doi.org/10.2351/1.4728136

28. Alsaidi M, Caballero A, Eze S, et al (2015) Study of laser metal interaction for pulsed nanosecond fibre laser. Dissertation, Cranfield University

29. John A (2015) Dissimilar welding of stainless steel to aluminium thin sheet using nano-second pulsed fibre laser. Dissertation, Cranfield University

30. Chmelickova H, Ctvrtlik R, Stranyanek M (2004) Pulsed laser welding of thin metals. In: Proc. SPIE 5445, Microwave and Optical Technology. pp 356-359

31. aalco (2019) Stainless steel-austenitic-304L properties. http://www. aalco.co.uk/datasheets/Stainless-Steel-14301-Sheet-and-PlateQuarto-Plate\%2D\%2DCPP-Plate 343.ashx. Accessed 1 Oct 2019

32. TRUMPF (2014) 100W G4 pulsed fibre laser specification interface manual. TRUMPF Lasers UK Ltd, Southampton

33. Ayoola WA, Suder WJ, Williams SW (2017) Parameters controlling weld bead profile in conduction laser welding. J Mater Process Technol 249:522-530. https://doi.org/10.1016/j.jmatprotec.2017. 06.026

34. Meco S, Cozzolino L, Ganguly S, Williams S, McPherson N (2017) Laser welding of steel to aluminium: thermal modelling and joint strength analysis. J Mater Process Technol 247:121-133. https:// doi.org/10.1016/j.jmatprotec.2017.04.002

35. Bauer F, Michalowski A, Kiedrowski T, Nolte S (2015) Heat accumulation in ultra-short pulsed scanning laser ablation of metals. Opt Express 23:1035-1043. https://doi.org/10.1364/oe.23.001035

Publisher's note Springer Nature remains neutral with regard to jurisdictional claims in published maps and institutional affiliations. 